Cochrane Database of Systematic Reviews

\title{
Interventions for the reduction of prescribed opioid use in chronic non-cancer pain (Review)
}

Eccleston C, Fisher E, Thomas KH, Hearn L, Derry S, Stannard C, Knaggs R, Moore RA

Eccleston C, Fisher E, Thomas KH, Hearn L, Derry S, Stannard C, Knaggs R, Moore RA. Interventions for the reduction of prescribed opioid use in chronic non-cancer pain. Cochrane Database of Systematic Reviews 2017, Issue 11. Art. No.: CD010323. DOI: 10.1002/14651858.CD010323.pub3.

www.cochranelibrary.com 
TABLE OF CONTENTS

ABSTRACT

PLAIN LANGUAGE SUMMARY

BACKGROUND

OBJECTIVES

METHODS

RESULTS

Figure 1.

Figure 2.

Figure 3.

DISCUSSION

AUTHORS' CONCLUSIONS

ACKNOWLEDGEMENTS

REFERENCES

CHARACTERISTICS OF STUDIES

APPENDICES

WHAT'S NEW

HISTORY

CONTRIBUTIONS OF AUTHORS

DECLARATIONS OF INTEREST

SOURCES OF SUPPORT

DIFFERENCES BETWEEN PROTOCOL AND REVIEW

NOTES

INDEX TERMS 
[Intervention Review]

\section{Interventions for the reduction of prescribed opioid use in chronic non- cancer pain}

Christopher Eccleston'1, Emma Fisher ${ }^{2}$, Kyla H Thomas ${ }^{3}$, Leslie Hearn4, Sheena Derry ${ }^{5}$, Cathy Stannard 6 , Roger Knaggs ${ }^{7}$, R Andrew Moore 8

${ }^{1}$ Centre for Pain Research, University of Bath, Bath, UK. ${ }^{2}$ Cochrane Pain, Palliative and Supportive Care Group, Pain Research Unit, Churchill Hospital, Oxford, UK. ${ }^{3}$ School of Social and Community Medicine, University of Bristol, Bristol, UK. ${ }^{4}$ Cochrane Pain, Palliative and Supportive Care Group, Pain Research Unit, Churchill Hospital, Oxford, UK. 50xford, UK. ${ }^{6}$ NHS Gloucestershire CCG, Brockworth, UK. ${ }^{7}$ School of Pharmacy, University of Nottingham, Nottingham, UK. 8Plymouth, UK

Contact: Christopher Eccleston, c.eccleston@bath.ac.uk.

Editorial group: Cochrane Pain, Palliative and Supportive Care Group.

Publication status and date: Stable (no update expected for reasons given in 'What's new'), published in Issue 5, 2021.

Citation: Eccleston C, Fisher E, Thomas KH, Hearn L, Derry S, Stannard C, Knaggs R, Moore RA. Interventions for the reduction of prescribed opioid use in chronic non-cancer pain. Cochrane Database of Systematic Reviews 2017, Issue 11. Art. No.: CD010323. DOI: 10.1002/14651858.CD010323.pub3.

Copyright @ 2017 The Cochrane Collaboration. Published by John Wiley \& Sons, Ltd.

\section{A B S T R A C T}

\section{Background}

This is the first update of the original Cochrane Review published in 2013. The conclusions of this review have not changed from the 2013 publication. People with chronic non-cancer pain who are prescribed and are taking opioids can have a history of long-term, high-dose opioid use without effective pain relief. In those without good pain relief, reduction of prescribed opioid dose may be the desired and shared goal of both patient and clinician. Simple, unsupervised reduction of opioid use is clinically challenging, and very difficult to achieve and maintain.

\section{Objectives}

To investigate the effectiveness of different methods designed to achieve reduction or cessation of prescribed opioid use for the management of chronic non-cancer pain in adults compared to controls.

\section{Search methods}

For this update we searched CENTRAL, MEDLINE, and Embase in January 2017, as well as bibliographies and citation searches of included studies. We also searched one trial registry for ongoing trials.

\section{Selection criteria}

Included studies had to be randomised controlled trials comparing opioid users receiving an intervention with a control group receiving treatment as usual, active control, or placebo. The aim of the study had to include a treatment goal of dose reduction or cessation of opioid medication.

\section{Data collection and analysis}

Two review authors independently extracted data and assessed risk of bias. We sought data relating to prescribed opioid use, adverse events of opioid reduction, pain, and psychological and physical function. We planned to assess the certainty of the evidence using the GRADE approach, however, due to the heterogeneity of studies, we were unable to combine outcomes in a meta-analysis and therefore we did not assess the evidence with GRADE. 


\section{Main results}

Three studies are new to this update, resulting in five included studies in total (278 participants). Participants were primarily women (mean age 49.63 years, SD $=11.74$ ) with different chronic pain conditions. We judged the studies too heterogeneous to pool data in a metaanalysis, so we have summarised the results from each study qualitatively. The studies included acupuncture, mindfulness, and cognitive behavioral therapy interventions aimed at reducing opioid consumption, misuse of opioids, or maintenance of chronic pain management treatments. We found mixed results from the studies. Three of the five studies reported opioid consumption at post-treatment and follow-up. Two studies that delivered 'Mindfulness-Oriented Recovery Enhancement' or 'Therapeutic Interactive Voice Response' found a significant difference between groups at post-treatment and follow-up in opioid consumption. The remaining study found reduction in opioid consumption in both treatment and control groups, and between-group differences were not significant. Three studies reported adverse events related to the study and two studies did not have study-related adverse events. We also found mixed findings for pain intensity and physical functioning. The interventions did not show between-group differences for psychological functioning across all studies. Overall, the risk of bias was mixed across studies. All studies included sample sizes of fewer than 100 and so we judged all studies as high risk of bias for that category.

\section{Authors' conclusions}

There is no evidence for the efficacy or safety of methods for reducing prescribed opioid use in chronic pain. There is a small number of randomised controlled trials investigating opioid reduction, which means our conclusions are limited regarding the benefit of psychological, pharmacological, or other types of interventions for people with chronic pain trying to reduce their opioid consumption. The findings to date are mixed: there were reductions in opioid consumption after intervention, and often in control groups too.

\section{PLAIN LANGUAGE SUMMARY}

\section{Reducing prescribed opioid use in adults with chronic non-cancer pain}

\section{Bottom line}

Based on the available evidence, we do not know the best method of reducing opioids in adults with chronic pain conditions. We found mixed results from a small number of studies included in this review.

\section{Background}

This is an updated review. The first review was published in 2013. About one in five adults suffer from moderate or severe chronic pain that is not caused by cancer. Some people with this type of pain are treated with opioids (typically with drugs such as morphine, codeine, oxycodone, fentanyl, or buprenorphine, either as tablets or as patches placed on the skin). It is not unusual for this medication to be ineffective or to stop working over time, and, sometimes, effective pain relief is not achieved despite doses being increased. Stopping using opioid drugs is not easy, especially when they have been used for some time, because stopping abruptly can cause unpleasant side effects.This review looked for high-quality studies (randomised controlled trials) of treatments to help adults safely stop taking opioids prescribed for their pain.

\section{Study characteristics}

We searched for studies up to January 2017. We found five studies, and they investigated 278 people. Most people included in the studies were women, who were around 50 years of age, and reported a mixture of chronic pain conditions (e.g. headache, back pain, muscle pain). The studies included acupuncture, mindfulness, and cognitive behavioral therapy as strategies to decrease the amount of opioids taken by adults with chronic pain.

\section{Key results}

No conclusions can be drawn from this small amount of information. Therefore, it is not clear whether these treatments decrease the amount of opioids in adults with chronic pain (primary outcome) or reduce pain intensity, physical ability or mood (secondary outcomes). Three studies did include negative effects of their treatment, and two reported that the participants did not have anything negative happen to them because of the trial they were in. Non-randomised studies, not included in this review, do indicate that for many people intensive rehabilitation packages may bring about major reduction in opioid use. Reducing prescribed opioid use in chronic non-cancer pain is an important topic in need of more systematic research.

\section{Quality of the evidence}

We were not able to judge the quality of evidence included in this review because the studies were so different and could not be combined. 


\section{B A C K G R O U N D}

Chronic pain of moderate or severe intensity and lasting six months or longer affects around $20 \%$ of adults and imposes significant reduction in quality of life (Moore 2013). Opioids have long been used in the treatment of acute and cancer pain, and over the last two decades there has been a marked increase in their prescription for chronic non-cancer pain (CNCP), especially in the USA, Australia, and Europe. Estimates of the numbers of people with CNCP treated with opioids are not commonly available, but one estimate for the UK indicates that almost one million people may use some form of opioid (Gallagher 2009).

Several randomised controlled trials suggested that opioids provide modest pain relief in the short to medium term (typical trial duration is 12 weeks; Furlan 2006; Kalso 2004). However, there is much less evidence that opioids provide long-term pain relief in CNCP (ASIPP 2012; Noble 2010), especially when statistical imputation methods are used in which withdrawal for any reason is regarded as treatment failure (and relevant to clinical practice), in comparison to the common practice of carrying forward the last observed pain readings to the end of the trial and using that measurement to estimate efficacy (Moore 2012; Steiner 2011).

Adverse events, principally sedation, impaired cognitive function, depression, constipation, and bladder dysfunction, are also common during opioid therapy (Benyamin 2008), with up to $80 \%$ of users suffering at least one adverse event (Moore 2005). Longterm opioid use can be associated with immune system depression, hormonal disturbances, and hyperalgesia (Benyamin 2008), as well as fractures (Miller 2011), and increased all-cause mortality in older people compared with other analgesics (Solomon 2010). Opioid use also carries risks of tolerance, dependence, and abuse.

Practicalities of the real world like prescribing restrictions for non-opioid analgesics, or guidelines that suggest early use of opioids, can mean that many people are prescribed opioid drugs, sometimes inappropriately. The American Society of Interventional Pain Physicians suggests that the majority of patients who start chronic opioid treatment continue with the treatment throughout their life (ASIPP 2012). On occasion, opioid doses are increased as a result of insufficient analgesia or the development of tolerance (i.e. requiring a higher dose to obtain the same therapeutic benefit). This can lead to people being prescribed very high doses of opioids, but still without acceptable pain relief. American opioid sales quadrupled between 1999 and 2010 (ASIPP 2012). In the USA increased prescribing is associated with higher rates of overdose and overdose death (Paulozzi 2011), but with an indication that $60 \%$ of CNCP opioid deaths occurred while opioids were used as directed (ASIPP 2012). However, there is some evidence to suggest that whilst the prescription of opioids remains high, it decreased between 2012 and 2015 in the USA (Guy 2017).

A number of professional societies worldwide have produced guidance advocating/promoting the judicious and careful use of opioids. The American Academy of Pain Medicine, the American Pain Society, and the American Society of Addiction Medicine jointly advise that healthcare providers should exercise caution when prescribing opioids, assessing circumstances and suitability on an individual basis (Chou 2009). Guidance in Washington State, USA (Washington State Agency Medical Group 2010) has passed into law (HB2876 2010). Current UK guidance is typical in that it recognises that prescription opioids can lead to problem use, and that there is considerable uncertainty in the literature about any long-term benefits of continued use.

There is growing concern that the widespread use of opioids has public health implications (Stannard 2012). The balance between benefit and risks generated during long-term therapy with opioids suggests that it may be neither clinically effective nor in patients' best interests to continue opioid prescription without adequate pain relief. There is, therefore, a potential need to facilitate and maintain opioid dose reduction. For many patients it is likely that long-term opioid treatment is continued even when benefit is not demonstrated, and greater patient benefits may accrue from opioid withdrawal. Patients who do not benefit from treatment in terms of pain, or who suffer unacceptable adverse events, should be helped to cease opioid treatment whilst concurrently addressing their pain (Ballantyne 2003).

There is a growing recognition that many patients will reach a state where the reduction of prescribed opioids is the desired and shared goal of both patient and clinician. This state is sometimes reached after a history of long-term, high-dose opioid use, making simple unsupervised cessation clinically challenging, if not impossible. This may occur, at least in part, because of the reluctance of patient and prescriber to reduce the opioid dose for fear of worsening pain, as well as issues of dependence and subsequent withdrawal symptoms.

There are many studies of methods of withdrawal from opioids; most, however, are undertaken in the context of addiction services for people with an opioid abuse problem. Our interest here was in the planned reduction or total withdrawal of opioids prescribed for pain management. Common opioid reduction techniques in the addiction field are instructive and include opioid replacement stabilisation and dose tapering, and may involve psychological treatments (Amato 2011). Inducing withdrawal under sedation using opioid antagonists such as naloxone, naltrexone, or nalmefene is possible (Gowing 2009; Gowing 2010) but is not recommended owing to unacceptable risks of adverse events. It is unclear whether similar interventions are effective when adjusted to CNCP in which treatment aims differ, or if other approaches are more appropriate.

\section{Description of the condition}

Patients

- with chronic pain of a non-cancer-related origin (such as neuropathic, musculoskeletal, visceral, or head pain)

- who are prescribed opioid medication for pain management

- who have a treatment goal of dose reduction or cessation of opioid medicine

\section{Description of the intervention}

The interventions included any clinical method that aimed to facilitate opioid withdrawal or dose reduction as a compulsory or optional aspect of treatment, as either a primary or a secondary outcome. The intervention could be pharmacological, physiological, psychological, or another, as long as its methods are documented clearly within the study. 


\section{How the intervention might work}

Different methods will have different mechanisms. In particular, we expect non-pharmacological treatment aimed at opioid reduction to operate principally through behaviour change, and pharmacological methods to operate principally by reducing or managing the adverse events of opioid use or opioid withdrawal.

\section{Why it is important to do this review}

Increased prescribing of opioids is a problem because of their potential to cause harm, along with issues of limited relief and tolerance. Given the known risks of opioid therapy, it is appropriate to continue to prescribe opioid medicines only to those people for whom the treatment produces acceptable benefits, weighed against any adverse events. Given evidence in many societies of huge increases in the use of medicinal opioids for CNCP, their limited effectiveness, and their adverse event profile, we can reasonably expect a large increase in people seeking clinical help to reduce or halt opioid consumption. An evidence summary of the most effective methods is needed, along with guidance on treatment development.

\section{O B JECT IVES}

To investigate the effectiveness of different methods designed to achieve reduction or cessation of prescribed opioid use for the management of chronic non-cancer pain in adults compared to controls.

\section{MET HOD S}

\section{Criteria for considering studies for this review Types of studies}

Included studies had to be randomised controlled trials (RCTs) comparing opioid users receiving an intervention with a control group receiving treatment as usual, active control, or placebo. The aim of the study had to include a treatment goal of dose reduction or cessation of opioid medicine. We excluded studies that included fewer than 10 participants in each arm at post-treatment.

\section{Types of participants}

Participants were adults (18 years of age or older) using prescription opioids for management of CNCP with a duration of at least three months. Pain conditions could include but were not limited to: neuropathic pain, myofacial pain, back pain, fibromyalgia, headache, abdominal, neck or musculoskeletal pain.

We excluded studies involving only participants with issues of addiction, abuse, dependence, or non-prescribed opioid use, and involving participants using opioids for pain relief during palliative care. This is because the aims of treatment for these populations differ substantially from those for the population of interest.

\section{Types of interventions}

We planned to include in this review a large variety of intervention types. Interventions could be based in pharmacology, physiology, psychology, spirituality, or another approach, provided that the underpinning methodology was well documented in the study and was valid. Eligible intervention types could include opioid antagonist treatment, dose tapering, or opioid replacement with other pain-relieving medication. Interventions could also involve physical therapy, massage, disability management, complementary therapies, or psychological approaches such as cognitive behavioural therapy, counselling, and coping techniques.

We excluded studies encompassing only interventions specifically for opioid addiction, medication overuse, dependence, or withdrawal symptoms.

\section{Types of outcome measures}

We extracted relevant outcomes before treatment, immediately after treatment, and at follow-up, at least three months later but no longer than a year. If there were two follow-up time points, the later would be chosen. Where appropriate, we extracted means and standard deviations of outcomes assessed with psychometrically tested measures.

\section{Primary outcomes}

The primary outcomes of this review are:

- prescribed opioid use in adults;

- adverse events related to opioid reduction.

\section{Secondary outcomes}

Secondary outcomes are:

- pain intensity/severity;

- psychological functioning;

- physical functioning.

\section{Search methods for identification of studies}

\section{Electronic searches}

We have conducted two searches to date. For the original review we searched the Cochrane Central Register of Controlled Trials (CENTRAL), MEDLINE, and Embase from 1999 to April 2013.

For this update we searched the same databases on 4 January 2017 to identify any further studies meeting the inclusion criteria:

- CENTRAL (via CRSO) - April 2013 to 4/1/17;

- MEDLINE (via OVID) - April 2013 to December week 1 2016;

- Embase (via OVID) - April 2013 to 2017 week 1.

We did not restrict the searches based on language. See Appendix 1 for search strategies.

\section{Searching other resources}

We searched the reference lists of retrieved papers and carried out a citation search to identify any potentially eligible papers not found through the electronic search. We also contacted the authors of studies identified for inclusion to obtain additional data relevant to this review and not included in the published articles. Finally, we searched Clinicaltrials.gov for additional trials that met eligibility.

\section{Data collection and analysis}

\section{Selection of studies}

We filtered search results initially by title and abstract, and obtained full copies of potentially eligible studies. Two review authors read the studies to confirm eligibility, with disagreements discussed and mediated by a third review author if necessary. In 
the first version of this review, we limited the selection of studies to those published from 2000 onwards, to reflect the major growth in opioid prescribing for CNCP after 2000.

\section{Data extraction and management}

Two review authors extracted data using a standard data extraction form to include details of participants, intervention method and duration, quantity and type of opioid used, study design, and treatment outcomes. We discussed any discrepancies with a third review author.

\section{Assessment of risk of bias in included studies}

We assessed risk of bias in the included studies using the Cochrane 'Risk of bias' tool (Higgins 2011) to assign judgements of high, low, or unclear risk of bias to sequence generation, allocation concealment, blinding, incomplete outcome data, selective reporting, and any other potential sources of bias in the included studies. Specifically for other sources of biases, we assessed the sample size as a risk of bias and coded any studies that included fewer than 100 participants as high risk of bias. Two authors (CE, EF) independently assessed risk of bias for each study and resolved disagreement by discussion. 'Risk of bias' assessments are included in the Characteristics of included studies.

We assessed the following for each study.

- Random sequence generation (checking for possible selection bias). We assessed the method used to generate the allocation sequence as: low risk of bias (any truly random process, e.g. random number table; computer random number generator); unclear risk of bias (method used to generate sequence not clearly stated); and high risk of bias (studies that included a biased randomisation procedure). We excluded studies that were not randomised.

- Allocation concealment (checking for possible selection bias). The method used to conceal allocation to interventions prior to assignment determines whether intervention allocation could have been foreseen in advance of, or during recruitment, or changed after assignment. We assessed the methods as: low risk of bias (e.g. telephone or central randomisation; consecutively numbered, sealed, opaque envelopes); unclear risk of bias (method not clearly stated).

- Blinding of outcome assessment (checking for possible detection bias). We assessed the methods used to blind outcome assessors from knowledge of which intervention a participant received. We assessed the methods as: low risk of bias (study had a clear statement that outcome assessors were unaware of treatment allocation, and ideally described how this was achieved); unclear risk of bias (study stated that outcome assessors were blind to treatment allocation but lacked a clear statement on how it was achieved).

- Incomplete outcome data (checking for possible attrition bias due to the amount, nature and handling of incomplete outcome data). We assessed the methods used to deal with incomplete data as: low risk (attrition fully reported and no differences between completers and non-completers); unclear risk of bias (attrition unclear or unclear differences between completers and non-completers); high risk of bias (attrition not reported or differences between completers and non-completers).

- Selective reporting (checking for reporting bias). We assessed whether all outcomes were reported in the paper as low risk of bias. High risk of bias would be given when data were not reported and not provided on request.

- Size of study (checking for possible biases confounded by small size). We assessed studies as being at low risk of bias (200 or more participants per treatment arm); unclear risk of bias (50 to 199 participants per treatment arm); high risk of bias (fewer than 50 participants per treatment arm).

\section{Measures of treatment effect}

We planned to use risk ratio (RR) to establish statistical difference, and number needed to treat for an additional beneficial outcome (NNTB) and number needed to treat for an additional harmful outcome (NNTH) as absolute measures of benefit or harm.

We defined a 'responder' to treatment as a participant who experienced at least a $50 \%$ reduction in opioid consumption, or achieved complete opioid withdrawal or a reduction of their intake to below 'high' dose, which we identified as $120 \mathrm{mg}$ a day oral morphine equivalent. Trials have previously shown that dose-related harms of taking more than $120 \mathrm{mg}$ a day of opioid drugs outweigh the benefits (Braden 2010; Morasco 2010; Sullivan 2010), and published guidelines, including those of the American Pain Society and the American Academy of Pain Medicine (Chou 2009), and by the Washington State Agency Medical Group 2010, recommend a cut-off at $120 \mathrm{mg}$ a day. A responder also had to have, at worst, no increase in pain as a result of the intervention. Both aspects of improvement had to be maintained for at least three months post intervention.

Our planned analyses included:

- Treatment versus control opioid reduction (post-treatment);

- Treatment versus control opioid reduction (follow-up);

- Treatment versus control pain intensity (post-treatment);

- Treatment versus control pain intensity (follow-up);

- Treatment versus control psychological functioning (posttreatment);

- Treatment versus control psychological functioning (follow-up);

- Treatment versus control physical functioning (post-treatment);

- Treatment versus control physical functioning (follow-up).

We planned to describe adverse events reported in all studies.

\section{Unit of analysis issues}

The unit of analysis was the individual participant.

\section{Dealing with missing data}

We used the intention-to-treat approach to deal with missing data. We would include in the analysis all participants who were randomised to treatment, and we assumed that those for whom follow-up data were not available were non-responders.

\section{Assessment of heterogeneity}

We anticipated that there would be significant clinical heterogeneity between studies (participants, conditions, interventions), so we planned to pool data using a random-effects model. 


\section{Assessment of reporting biases}

We planned to assess publication bias by estimating the number of unpublished null studies needed to make a clinical finding likely to be unstable or irrelevant (Moore 2008). Unfortunately, this was not possible because we were not able to calculate any effect sizes.

\section{Data synthesis}

We planned to combine data using Review Manager 5 (RevMan 5) (RevMan 2014). We planned to include dichotomous outcome analysis for the number of people who achieved a $50 \%$ reduction in opioid consumption. For this analysis, we planned to use Mantel-Haenszel statistics, and report risk ratio outcomes. We described any adverse events in the trials. For our secondary outcomes, we planned to analyse pain intensity, psychological functioning, and physical functioning in separate analyses using inverse variance methods in a random-effects model. We planned to summarise heterogeneity using 12 statistics (Higgins 2003), which we planned to interpret following Deeks 2011 reference points of $0 \%$ to $40 \%$ : might not be important; $30 \%$ to $60 \%$ : may represent moderate heterogeneity; $50 \%$ to $90 \%$ : may represent substantial heterogeneity; $75 \%$ to $100 \%$ : considerable heterogeneity.

If data were homogeneous we planned to combine data in a meta-analysis, and if heterogeneous to describe the findings from the studies separately, focusing on our primary and secondary outcomes.

\section{Quality of the evidence}

We planned that two review authors (CE, EF) would independently rate the quality of the outcomes. We planned to use the GRADE approach to rank the quality of the evidence using RevMan 5 (RevMan 2014), and the guidelines provided in chapter 12 of the Cochrane Handbook for Systematic Reviews of Interventions (Schünemann 2011).

The GRADE approach uses five considerations (study limitations, consistency of effect, imprecision, indirectness and publication bias) to assess the quality of the body of evidence for each outcome. The GRADE system uses the following criteria for assigning grade of evidence.

- High: we are very confident that the true effect lies close to that of the estimate of the effect;

- Moderate: we are moderately confident in the effect estimate; the true effect is likely to be close to the estimate of effect, but there is a possibility that it is substantially different;

- Low: our confidence in the effect estimate is limited; the true effect may be substantially different from the estimate of the effect;

- Very low: we have very little confidence in the effect estimate; the true effect is likely to be substantially different from the estimate of effect.
We planned to decrease our rating by one $(-1)$ or two $(-2)$ if we identified:

- serious (-1) or very serious (-2) limitation to study quality;

- important inconsistency $(-1)$;

- some (-1) or major (-2) uncertainty about directness;

- imprecise or sparse data (-1);

- high probability of reporting bias (-1).

\section{'Summary of findings' table}

We planned to include a 'Summary of findings' table to present the main findings for comparison of interventions to reduce opioid consumption versus control in a transparent and simple tabular format. In particular, we planned to include key information concerning the quality of evidence, the magnitude of effect of the interventions examined, and the sum of available data on the outcomes of reduction of opioid consumption, adverse events, pain intensity, psychological functioning, and physical functioning. We plan to include a 'Summary of findings' table in the next update, providing sufficient evidence is available.

\section{Subgroup analysis and investigation of heterogeneity}

We planned subgroup analyses to assess the effect of entry dose on intervention efficacy, and to compare outcomes between pain conditions or intervention type if sufficient data were available.

\section{Sensitivity analysis}

We planned to perform a sensitivity analysis should we suspect that studies with high risk of bias were significantly skewing results of a comparison, removing studies from the analysis to assess their influence.

\section{RES U L T S}

\section{Description of studies}

\section{Results of the search}

This is an updated search of a review previously published in 2013 (Windmill 2013). During the first search of databases from 1999 to April 2013, we included three papers that reported on two studies (Naylor 2010; Zheng 2008). We searched CENTRAL, MEDLINE and Embase for studies eligible for inclusion. In the second search from April 2013 to January 2017 we identified 3480 abstracts; 2878 abstracts after duplicates were removed (Figure 1). We identified two new studies that met eligibility for this update (Garland 2014; Sullivan 2017). We contacted all first authors of the included studies for additional studies that we had not captured in our search, and identified one further study that met eligibility (Jamison 2010). Therefore, three studies are new to this update (Garland 2014; Jamison 2010; Sullivan 2017), resulting in five studies overall. 


\section{Figure 1. Study flow diagram}

Number of studies included
in previous version of review
$(N=2)$

\section{1 additional record identified through other sources}

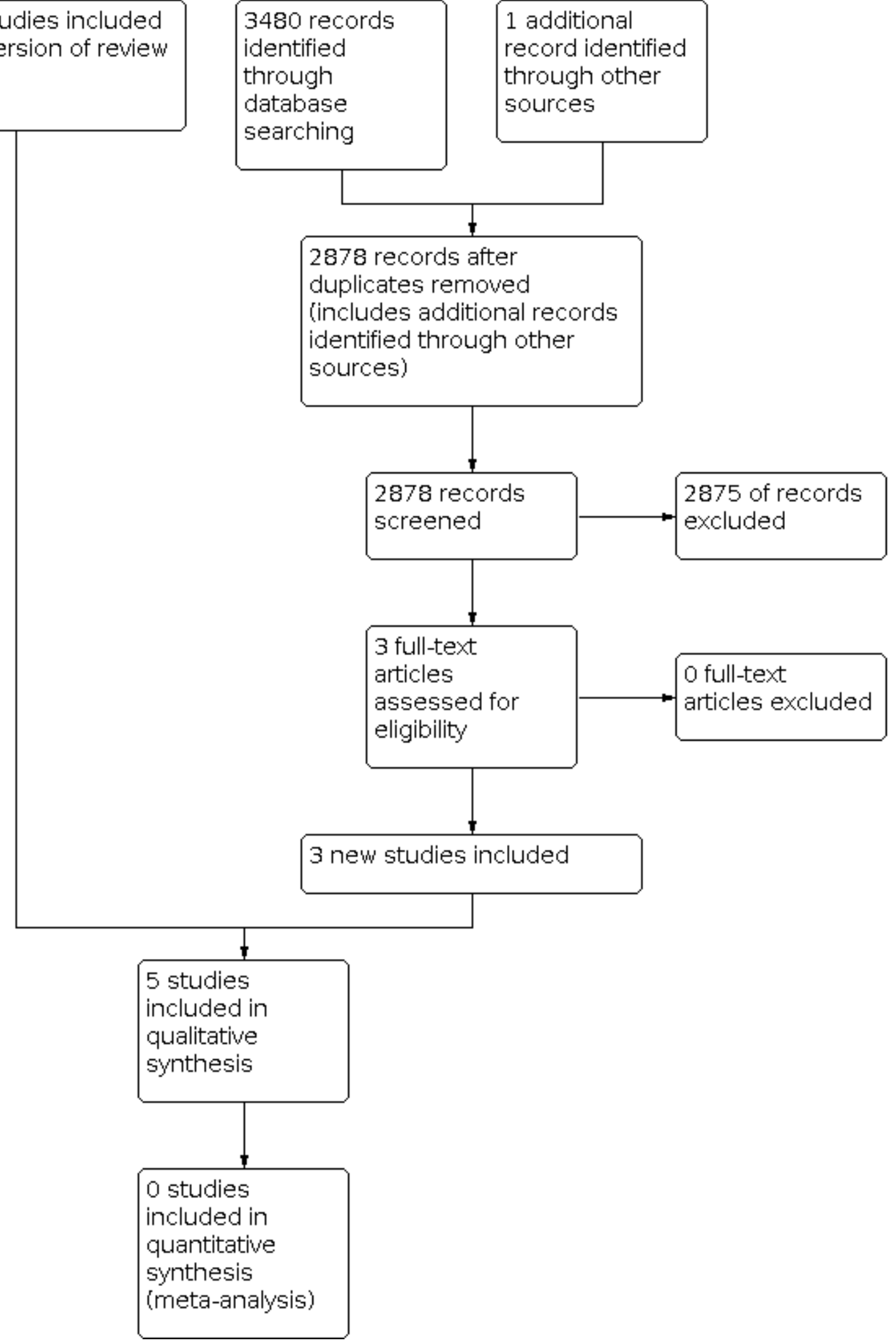




\section{Included studies}

Five studies met the inclusion criteria (Garland 2014; Jamison 2010; Naylor 2010; Sullivan 2017; Zheng 2008) that included 278 participants with chronic pain (women $=184$; men $=94$; mean age $=49.63$ years, $\mathrm{SD}=11.74$ ). Three studies included participants with mixed chronic pain conditions, Naylor 2010 exclusively included participants with chronic musculoskeletal pain, and participants in Jamison 2010 reported chronic neck or back pain. Jamison 2010; Naylor 2010, Sullivan 2017, and Zheng 2008 reported that the average pain duration was 12.68 years $(S D=10.72)$.

Of the five studies, two studies aimed to reduce opioid consumption via cognitive behavioural therapy (CBT) (Sullivan 2017) or electroacupuncture (Zheng 2008). Two studies aimed to reduce opioid misuse in people with chronic pain (Garland 2014; Jamison 2010). These studies delivered CBT or mindfulness treatments to the participants. One study aimed to increase treatment compliance and adherence in people with chronic pain receiving a pain-management treatment (Naylor 2010). Here, the authors delivered CBT to everyone, and then provided a therapeutic interactive voice response to participants randomised to the treatment condition to improve maintenance of treatment. Two studies compared treatment to active controls and the remaining studies used standard care controls. Full details can be found in the Characteristics of included studies table.

In addition to published data, two author groups (Naylor 2010; Zheng 2008) provided additional data for the outcomes of pain and psychological functioning (Appendix 2). The remaining studies included data pertinent to this review meaning that we did not need to contact them for additional data.

\section{Excluded studies}

We excluded seven studies from this review, none new to this update. Three did not meet methodological standards (Crisostomo 2008; Krymchantowski 2003; Townsend 2008), while four did not have opioid reduction as a primary aim (Hale 2007; Potter 2010; Roland 2011; Weinstein 2006). Full details are available in the Characteristics of excluded studies table.

\section{Risk of bias in included studies}

We assessed risk of bias using the Cochrane 'Risk of bias' tool (Higgins 2011). Justification for judgements can be found in Characteristics of included studies and the figures of bias assessments in Figure 2 and Figure 3.

\section{Figure 2. Risk of bias graph: review authors' judgements about each risk of bias item presented as percentages across all included studies}

Random sequence generation (selection bias)

Allocation concealment (selection bias)

Blinding of outcome assessment (detection bias): All outcomes Incomplete outcome data (attrition bias): All outcomes Selective reporting (reporting bias)

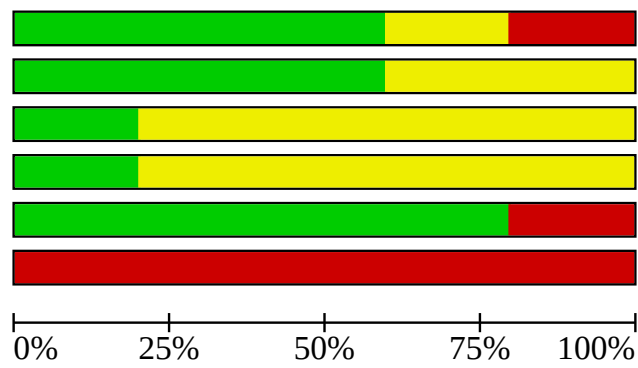
Size

Low risk of bias

Unclear risk of bias

High risk of bias 
Figure 3.

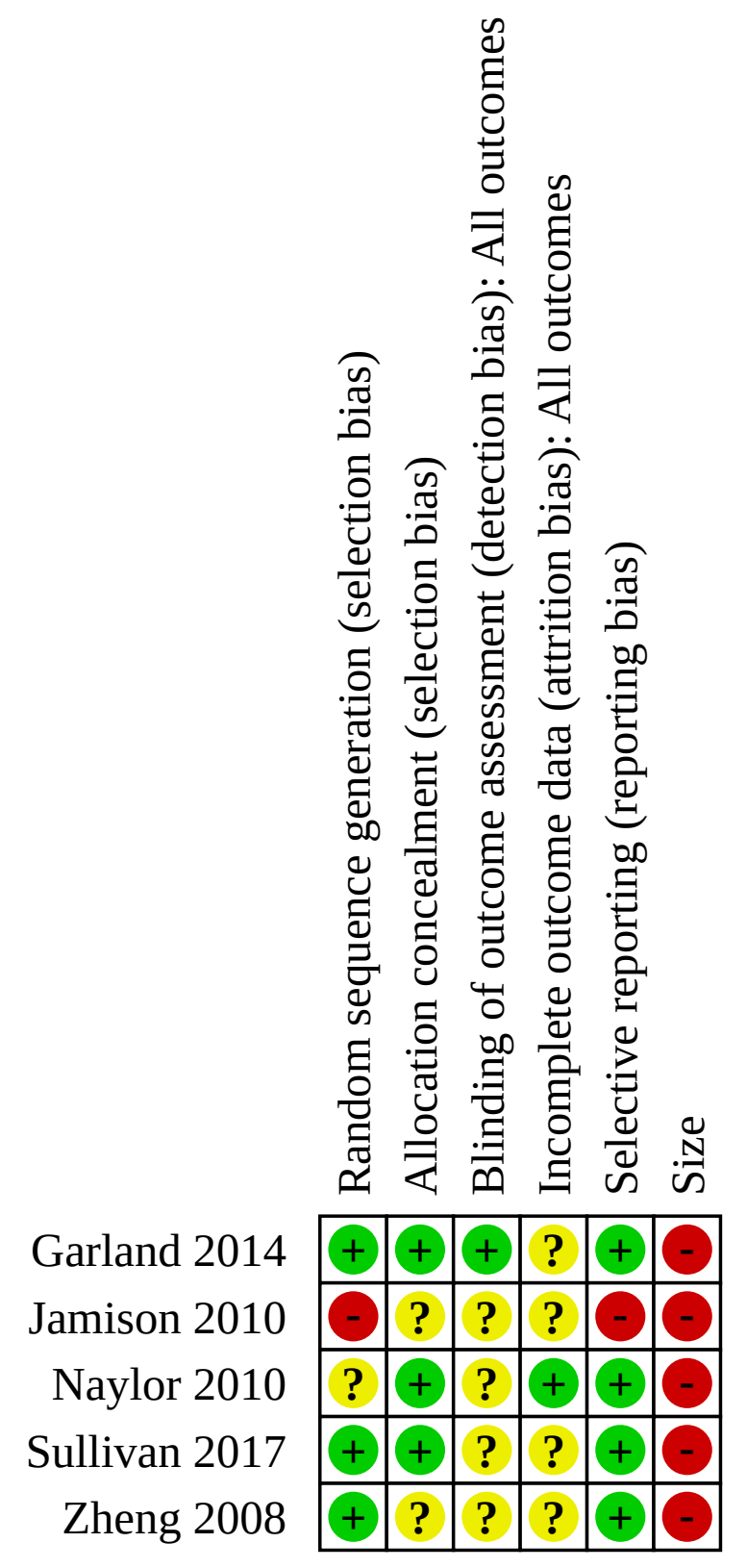

\section{Allocation}

\section{Random sequence generation}

Three studies described sound randomisation procedures and we judged them to be low risk of bias, one study did not give a clear description, and we judged one study to have a high risk of bias as it randomised people based on the order that they were entered into the trial.

\section{Allocation concealment}

Three studies provided adequate descriptions of allocation concealment and we gave a low risk of bias rating, whilst two studies did not describe methods to conceal allocation and we marked them as unclear risk. 


\section{Blinding}

\section{Detection bias}

We rated one study as low risk of bias for blinding outcome assessors, and the remaining four studies as unclear risk.

\section{Performance bias}

We excluded performance bias from this review as it is not possible to blind personnel who are delivering psychological treatments, or participants who are receiving them.

\section{Incomplete outcome data}

For attrition bias, one study did not have any dropouts and was marked as low risk of bias. The four further studies were judged to be unclear because they did not note differences between completers and non-completers.

\section{Selective reporting}

Most studies reported data for all outcomes and were marked as low risk of bias. However, one study had missing data and was rated as high risk of bias.

\section{Other potential sources of bias}

We rated all studies as high risk of bias for including small sample sizes (fewer than 50 participants per treatment arm).

\section{Effects of interventions}

All studies provided data to be analysed. However, due to the heterogeneity of the studies, we did not pool data in a metaanalysis. Therefore, we did not conduct GRADE analyses. We describe findings from each study.

\section{Primary Outcomes}

\section{Opioid use}

Garland 2014 compared a Mindfulness-Oriented Recovery Enhancement (MORE) treatment with a support group control. They did not assess objective opioid use before or after the trial. However, desire for opioids and opioid misuse was reported. Authors reported that the MORE group had a significantly lower desire for opioid consumption post treatment, but results were not maintained at follow-up. The MORE group also self-reported significantly lower opioid misuse (63\%) compared to the support group (32\%) at post-treatment. However, similar to the desire for opioids, participants did not differ at follow-up.

Jamison 2010 did not assess objective opioid use before or after the trial. A self-reported, prescription drug-use questionnaire was taken, but differences between groups at post-treatment were not reported.

Naylor 2010 compared Therapeutic Interactive Voice Response (TIVR) through a computer for four months with usual treatment, following CBT delivered to all participants for 11 weeks. The TIVR group ( $n=26,14$ of whom were using opioids at baseline) reported a significant decrease in opioid use from baseline at both four- and eight-month follow-ups, with three participants stopping opioid use entirely. The standard care control ( $n=25,15$ of whom were using opioids at baseline) significantly increased opioid consumption from baseline to the eight-month follow-up, and three more participants began opioid treatment. At post-treatment and eight-month follow-up, the difference in mean opioid dose was significant, with the TIVR group using less than the standard care control.

Sullivan 2017 randomised 35 participants to an opioid-tapering support intervention $(n=18)$ or usual care $(n=17)$. Both the treatment and control group reduced their intake of opioids at 22 weeks, and there was no significant difference between groups (morphine-equivalent doses (MED) taper support $=111.94, \mathrm{SD}=$ 153.63; usual care $=169.85, \mathrm{SD}=201.31$ ). Similarly at follow-up, no between-group differences were identified (MED) taper support $=99.51, \mathrm{SD}=151.99$; usual care $=138.24, \mathrm{SD}=155.85)$. There was also no significant difference in the percent reduction from baseline and 22 weeks or 34 weeks for either group. However, opioid consumption was reduced compared to baseline levels.

Zheng 2008 randomised participants to receive either real electroacupuncture (REA; $n=17$ ) or sham electroacupuncture (SEA; $n=18$ ) for 20 minutes twice a week for six weeks. Opioid consumption varied considerably within each group, and the mean consumption at baseline differed between groups, being $462( \pm 463)$ $\mathrm{mg}$ a week in the REA group and $296( \pm 288) \mathrm{mg}$ a week in the SEA group. Participants in both groups who completed the six weeks of treatment $(\mathrm{REA}=12 ; \mathrm{SEA}=14)$ reported a significant reduction in opioid consumption between baseline and the end of treatment at eight weeks, of $64 \%$ and $46 \%$ in the REA and SEA groups, respectively. In an intention-to-treat analysis, the reductions were $39 \%$ and $26 \%$. The difference between groups was not statistically significant. At follow-up at 20 weeks (REA = 9; SEA = 14), opioid consumption had gradually increased in the REA group and was significantly higher at 20 weeks than at eight weeks, while in the SEA group there was no significant change.

\section{Adverse events}

Garland 2014 did not report the occurrence of adverse events. When we contacted the study authors, they reported that there had been no adverse events.

Jamison 2010 reported adverse events across all participants of dry mouth $(44.9 \%)$, constipation (38.4\%) sweating (37.5\%), memory lapse $(28.4 \%)$, weakness $(24.1 \%)$, itching $(23.9 \%)$, and headaches (28.4\%). The treatment group reported lower rates of constipation and itching, but higher vision problems. The control group reported more severe constipation, sneezing, and nightmares than the treatment group.

Naylor 2010 did not report on adverse events, but contact with the study authors confirmed that there were no adverse events associated with treatment.

Sullivan 2017 reported one severe study-related adverse event in the taper-support group. The study psychiatrist prescribed nortriptyline during the participant's initial psychiatric evaluation, which the participant had a severe reaction to. This medication was discontinued and symptoms resolved.

Zheng 2008 reported a total of 33 adverse events during the treatment period with REA, and 19 with SEA, none of which were classed as serious adverse events. Opioid-based adverse events decreased from baseline to eight weeks after treatment by $40 \%$ in the REA group and $45 \%$ in the SEA group. 


\section{Secondary Outcomes}

\section{Pain intensity}

These numbers are from data supplied by the study authors (Appendix 2) and differ slightly from the published data.

Garland 2014 used the Brief Pain Inventory, pain intensity subscale and found that the MORE group reported significantly lower pain intensity at post-treatment (Mean $(M)=4.86, S D=1.38$ ) that met the threshold for minimally clinically significant change, in comparison to the support group (SG) control group ( $M=5.71, S D=1.58$ ). This between-group difference was maintained at follow-up (MORE $M=$ $4.77, \mathrm{SD}=1.95 ; \mathrm{SG} M=6.10, \mathrm{SD}=1.48$ ).

Jamison 2010 assessed pain using the Brief Pain Inventory, pain intensity subscale. However, post-treatment means and standard deviations were not reported.

Naylor 2010 analysed pain using the McGill Pain Questionnaire, reported in Naylor 2008 (Naylor 2010). The TIVR group reported a decrease in typical pain from baseline to eight months from $5.7 / 10$ to $3.4 / 10$, and the standard care control from 6.8 to 5.7. The difference between groups was statistically significant.

Sullivan 2017 assessed pain intensity using the Brief Pain Inventory, pain severity subscale. There was no significant difference between groups at 22 weeks (taper support $=4.72, \mathrm{SD}=1.62$; usual care $=$ $5.77, \mathrm{SD}=1.92$ ) or at 34 weeks (taper support $=4.67, \mathrm{SD}=1.79$; usual care $=6.16, \mathrm{SD}=2.64)$.

Zheng 2008 used the Visual Analogue Scale to assess pain intensity. Average pain at baseline was 4.9/10 in the experimental group and $5.6 / 10$ in the control group, and post-treatment scores were 4.2 and 5.4 , respectively. No differences were detected between groups. At 20 weeks average pain scores were 3.6 and 4.6 .

\section{Psychological function}

Garland 2014 assessed depression using the Calgary Symptoms of Stress Inventory, depression subscale. There were no betweengroup differences at post-treatment $(\mathrm{MORE}=8.20, \mathrm{SD}=7.09$; $\mathrm{SG}=$ 10.76, SD =6.44). Depression was not assessed at follow-up.

Jamison 2010 reported that the control group had significantly higher scores compared to the treatment group on anxiety and depression measures (treatment $=6.06, \mathrm{SD}=3.55$; standard care $=$ $9.00, \mathrm{SD}=3.39$; treatment $=8.1, \mathrm{SD}=4.8$; standard care $=9.06, \mathrm{SD}$ $=4.11$ ) respectively.

Naylor 2010 reported a decrease in scores of depression throughout the study, using the Beck Depression Inventory. There were significant between-group differences, favouring lower scores in the experimental group compared to the control group at posttreatment $(\mathrm{TIVR}=10.4, \mathrm{SD}=6.4$; standard care $=16.7, \mathrm{SD}=11.2)$ and eight-month follow-up $(\mathrm{TIVR}=8.1, \mathrm{SD}=4.8$; standard care $=14.9$, $\mathrm{SD}=8.7)$.

Sullivan 2017 assessed depression using the Patient Health Questionnaire-9. There were no significant group differences at 22 weeks (taper support $=8.88, \mathrm{SD}=7.49$; usual care $=11.27, \mathrm{SD}=6.58$ ), or at 34 weeks (taper support $=9.00, \mathrm{SD}=5.80$; usual care $=11.13$, $\mathrm{SD}=7.53)$
Zheng 2008 reported a significant decrease in depression scores (Beck Depression Inventory) from baseline to post-treatment at eight weeks in the REA group, from 18 to 17 . Scores in the SEA group also decreased, from 19 to 15 . At final measurement at 20 weeks, the REA group mean score was 14 , and the SEA group mean score was 15 . There was no significant difference between the groups at either time point.

\section{Physical function}

Garland 2014 assessed functional interference with the Brief Pain Inventory. The MORE group reported a significantly lower pain-related functional interference compared to the SG at posttreatment (MORE M $=5.22 \mathrm{SD}=1.88 ; \mathrm{SG} M=6.90, \mathrm{SD}=1.50$ ), and the between-groups difference was maintained at follow-up (MORE M $=4.60 \mathrm{SD}=2.66 ; \mathrm{SG} \mathrm{M}=6.75, \mathrm{SD}=1.86$ ).

Jamison 2010 reported that there were no differences between treatment and control at six-month post-treatment on the Pain Disability Index.

Naylor 2010 reported physical function using the SF-36 Physical Function composite scale. The experimental group showed a small increase (from 31/100 to 40/100) in functioning over eight months, while the control group did not (29/100 to $31 / 100)$. The difference between groups was statistically significant.

Sullivan 2017 assessed functional interference with the Brief Pain Inventory, interference subscale. Significant group differences were identified at 22 weeks (taper support $=4.55, \mathrm{SD}=2.39$; usual care $=6.38, \mathrm{SD}=2.11$ ). There were also group differences at 34 weeks, but these were only trending in favour of the taper support group (taper support $=4.49, \mathrm{SD}=2.08$; usual care $=6.05, \mathrm{SD}=2.72$ ).

Zheng 2008 did not measure physical function.

\section{ISC US S I O N}

\section{Summary of main results}

We included three new studies in this update. However, there remain no adequate data from which to draw any conclusions from five small studies with different interventions and only 278 treated participants. Therefore, our conclusions for this review have not changed.

\section{Overall completeness and applicability of evidence}

Because of the very small number of included studies, for the previous version of the review we decided to additionally investigate methods of prescription opioid reduction that were not randomised controlled trials, in case this was a more commonly used study design. In 2013, we looked at papers from the previous search results and additional reference searching. Inclusion criteria remained the same as in the main search, excepting the criteria of randomised controlled design. The overall completeness and applicability from the previous update are still relevant for this update, due to the lack of evidence in this area and the complexity of designing and conducting an RCT to investigate this problem.

In contrast to the randomised evidence, there was a much larger body of evidence from observational studies. A threeweek, outpatient, intensive, multidisciplinary pain rehabilitation programme conducted at the Mayo Clinic Pain Rehabilitation Center demonstrated large reductions in medication use, 
particularly in use of opioids, in a number of publications in recent years. The three-week programme included stretching, goal setting, stress management, physical therapy, pain management, relaxation, and occupational therapy (Mayo 2017). Typical opioid use in patients at admission was high, often above $40 \%$ and as high as $100 \%$, and at discharge and follow-up was low, often below $10 \%$. The analyses were retrospective or longitudinal, and not randomised, but represented an interesting body of additional data. Results like these were obtained for 159 patients with fibromyalgia (Hooten 2007), for 383 patients after fusion or nonfusion spinal surgery, or no surgery (Crisostomo 2008), in a group of 411 patients with a wide range of age and non-cancer pain conditions (Darchuk 2010), and for 634 chronic pain patients of different smoking status (Hooten 2009). In a group of 213 patients all taking opioids on admission, the rate of opioid use at discharge was $7 \%$ and remained low for as long as six months after admission (Townsend 2008).

Change in medication use, including opioid medication use, is a common feature of multimodal and multi-component programmes of cognitive behavioural therapy for chronic pain. The evidence for such programmes in improving disability status and reducing the impact of mental health outcomes is promising (Williams 2012). At present, however, it is not possible to extract and describe the components of such programmes for their effectiveness on medication consumption outcomes, although individual trials report positive effects. A challenge will be to determine methods of analysis, if possible, of such treatment packages with multiple components addressing multiple outcomes.

Others have sought evidence from literature reviews to prevent opioid over-use, and have put forward what is claimed to be an evidence-based algorithmic approach (Atluri 2012).

Legislation (HB2876 2010) has had a major effect on opioid prescribing in Washington State, where a de-facto limit of $120 \mathrm{mg}$ oral morphine equivalent a day is suggested, with higher doses available after consultation with a specialist. An interim assessment showed that about half of physicians followed guidance on opioid prescribing, and that about $90 \%$ of them found it useful (DLI 2009). A survey has shown large falls in opioid prescribing (27\%), and in the proportion taking more than $120 \mathrm{mg}$ a day oral morphine equivalents (35\%), as well as in opioid-related deaths (50\%) (Franklin 2012). The benefits of treating patients with chronic pain continue to show a lack of long-term benefit. A systematic review assessing opioid consumption comparing to placebo or no opioids did not find studies assessing long-term follow-up (i.e. one year). Opioids were found to be frequently abused and misused in chronic pain samples, and associated with dependence, fractures, and myocardiac infarctions (Chou 2015). Further, recent recommendations from the Centres for Disease Control state that opioid therapy should not be given to people with chronic pain (not associated with a life-limiting condition) due to potential harm and lack of medium- and long-term benefit (Dowell 2016).

\section{Quality of the evidence}

The evidence base identified by this review is small and limited and we were unable to perform a GRADE assessment of the certainty of evidence in this area. The individual studies have small numbers of participants, and overall we have evidence of the experience of only
278 chronic pain patients. There is a heterogeneity of interventions and outcome reporting. Poor reporting is common, meaning that the risk of bias was often unclear or high.

\section{Potential biases in the review process}

We were not aware of any biases in the review process, although there was a potential for bias in searching for studies. While the intention to reduce opioid use may have been clear, possible interventions may have been disparate.

\section{Agreements and disagreements with other studies or reviews}

We found no other similar reviews.

\section{AUTHORS' CONCLUSIONS}

\section{Implications for practice}

There were too few data in this review to permit any comments about implications for practice.

\section{Implications for research}

\section{General implications}

There is an urgent need for more research. There is a growing population of people with chronic pain, who also have chronic use of opioids, which are thought to be untherapeutic and for whom reduction is a primary clinical goal. We are unable to reduce our uncertainty around any treatment offered to these people for this purpose.

\section{Design}

We need more randomised controlled trials of theoretically grounded behaviour-change interventions that focus on opioid medication use in the context of medically treated chronic pain. There should be no fewer than 100 participants in each trial arm.

\section{Measurement (endpoints)}

More work is needed to agree the best endpoints for treatments of medication reduction. Measures of the type of opioid and the median daily opioid dose in morphine equivalents consumed in a particular time period are critical to report. In addition, measures of patient-relevant outcomes such as mood, social functioning, and personal role functioning are also important to assess.

\section{ACK N O WLEDGEMENTS}

We acknowledge the help of Jane Hayes and Jo Abbott in developing the search strategy, and the authors of the included studies in providing additional data. We would also like to thank Jude Windmill for contributing to the original publication.

Cochrane Review Group funding acknowledgement: this project was supported by the National Institute for Health Research, via Cochrane Infrastructure funding to Cochrane Pain, Palliative and Supportive Care (PaPaS). The views and opinions expressed therein are those of the review authors and do not necessarily reflect those of the Systematic Reviews Programme, NIHR, NHS or the Department of Health. 


\section{RE F E R E N C E S}

\section{References to studies included in this review}

Garland 2014 \{published data only\}

Garland, EL, Manusov EF, Froeliger B, Kelly A, Williams JM, Howard MO. Mindfulness-oriented recovery enhancement for chronic pain and prescription opioid misuse: results from an early stage randomized controlled trial. Journal of Consulting and Clinical Psychology 2014;82(3):448-59.

\section{Jamison 2010 \{published data only\}}

Jamison RN, Ross EL, Michna E, ChenL LQ, Holcomb C, Wasan AD. Substance misuse treatment for high-risk chronic pain patients on opioid therapy: a randomized trial. Pain 2010;150:390-400.

\section{Naylor 2010 \{published data only\}}

Naylor MR, Keefe FJ, Brigidi B, Naud S, Helzer JE. Therapeutic interactive voice response for chronic pain reduction and relapse prevention. Pain 2008;134(3):335-45. [DOI: 10.1016/ j.pain.2007.11.001]

* Naylor MR, Naud S, Keefe FJ, Helzer JE. Therapeutic interactive voice response (TIVR) to reduce analgesic medication use for chronic pain management. Journal of Pain 2010;11(12):1410-9. [DOI: 10.1016/j.jpain.2010.03.019]

\section{Sullivan 2017 \{published data only\}}

Sullivan MD, Turner JA, DiLodovico C, D’Appollonio A, Stephens K, Chan Y. Prescription opioid taper support for outpatients with chronic pain: a randomized controlled trial. Journal of Pain 2017;18(3):308-18.

\section{Zheng 2008 \{published data only\}}

Zheng Z, Gue RJ, Helme RD, Muir A, Costa CD, Xue CCL. The effect of electroacupuncture on opioid-like medication consumption by chronic pain patients: a pilot randomized controlled trial. European Journal of Pain 2008;12(5):671-6. [DOI: 10.1016/j.ejpain.2007.10.003]

\section{References to studies excluded from this review}

Crisostomo 2008 \{published data only\}

Crisostomo RA, Schmidt JE, Hooten WM, Kerkvliet JL, Townsend CO, Bruce BK. Withdrawal of analgesic medication for chronic low-back pain patients: improvement in outcomes of multidisciplinary rehabilitation regardless of surgical history. American Journal of Physical Medicine and Rehabilitation 2008;87(7):527-36. [DOI: 10.1097/PHM.0b013e31817c124f]

\section{Hale 2007 \{published data only\}}

Hale ME, Ahdieh H, Ma T, Rauck R. Efficacy and safety of OPANA ER (oxymorphone extended release) for relief of moderate to severe chronic low back pain in opioid-experienced patients: a 12-week, randomized, double-blind, placebo-controlled study. The Journal of Pain 2007;8(2):175-84. [DOI: 10.1016/ j.jpain.2006.09.011]
Krymchantowski 2003 \{published data only\}

Krymchantowski AV, Moreira PF. Out-patient detoxification in chronic migraine: comparison of strategies. Cephalalgia 2003;23:982-93. [DOI: 10.1046/j.1468-2982.2003.00648.x ]

\section{Potter 2010 \{published data only\}}

Potter JS, Chakrabarti A, Domier CP, Hillhouse MP, Weiss RD, Ling W. Pain and continued opioid use in individuals receiving buprenorphine-naloxone for opioid detoxification: secondary analyses from the clinical trials network. Journal of Substance Abuse Treatment 2010;38 (Suppl 1):S80-6. [DOI: 10.1016/ j.jsat.2009.12.007]

\section{Roland 2011 \{published data only\}}

Roland CL, Setnik B, Cleveland JM, Brown DA. Clinical outcomes during opioid titration following initiation with or conversion to Remoxy ${ }^{\circledast}$, an extended-release formulation of oxycodone. Postgraduate Medicine 2011;123(4):148-59. [DOI: 10.3810/ pgm.2011.07.2314]

\section{Townsend 2008 \{published data only\}}

Townsend CO, Kerkvliet JL, Bruce BK, Rome JD, Hooten WM, Luedtke CA, et al. A longitudinal study of the efficacy of a comprehensive pain rehabilitation program with opioid withdrawal: comparison of treatment outcomes based on opioid use status at admission. Pain 2008;140(1):177-89. [DOI: 10.1016/j.pain.2008.08.005]

\section{Weinstein 2006 \{published data only\}}

Weinstein SM, Shi M, Buckley BJ, Kwarcinski MA. Multicenter, open-label, prospective evaluation of the conversion from previous opioid analgesics to extended-release hydromorphone hydrochloride administered every 24 hours to patients with persistent moderate to severe pain. Clinical Therapeutics 2006;28(1):86-98. [DOI: 10.1016/j.clinthera.2006.01.010]

\section{References to ongoing studies \\ NCT02602535 \{published data only\}}

Garland E. Mindfulness-oriented recovery enhancement for chronic pain and prescription opioid misuse in primary care. clinicaltrials.gov/ct2/show/NCT02602535?term=MindfulnessOriented+Recovery+Enhancement\&rank=12015 (Accessed 1st November 2017). [NCT02602535]

\section{NCT02935621 \{published data only\}}

Garland E. Behavioral interventions for active duty service members and veterans with chronic pain. clinicaltrials.gov/ ct2/show/NCT02935621 2016 (Accessed 1st November 2017). [NCT02935621]

\section{Additional references}

\section{Amato 2011}

Amato L, Minozzi S, Davoli M, Vecchi S. Psychosocial and pharmacological treatments versus pharmacological treatments for opioid detoxification. Cochrane Database of 
Systematic Reviews 2011, Issue 9. Art. No: CD005031. [DOI: 10.1002/14651858.CD005031.pub4]

\section{ASIPP 2012}

Manchikanti L, Abdi S, Atluri S, Balog C, Benyamin R, Boswell M, et al. American Society of Interventional Pain Physicians (AISPP) guidelines for responsible opioid prescribing in chronic noncancer pain: part 1 - evidence assessment. Pain Physician 2012;15(3 Suppl):S1-65.

\section{Atluri 2012}

Atluri S, Akbik H, Sudarshan G. Prevention of opioid abuse in chronic non-cancer pain: an algorithmic, evidence based approach. Pain Physician 2012;15(3 Suppl):ES177-89.

\section{Ballantyne 2003}

Ballantyne JC, Mao J. Opioid therapy for chronic pain. New England Journal of Medicine 2003;349(20):1943-53. [DOI: 10.1056/NEJMra025411]

\section{Benyamin 2008}

Benyamin R, Trescot AM, Datta S, Buenaventura R, Adlaka R, Sehgal N, et al. Opioid complications and side effects. Pain Physician 2008;11(2 Suppl):S105-20.

\section{Braden 2010}

Braden JB, Russo J, Fan MY, Edlund MJ, Martin BC, DeVries A, et al. Emergency department visits among recipients of chronic opioid therapy. Archives of Internal Medicine 2010;170(16):1425-32. [DOI: 10.1001/archinternmed.2010.273]

\section{Chou 2009}

Chou R, Fanciullo GJ, Fine PG, Adler JA, Ballantyne JC, Davies P, et al. Clinical guidelines for the use of chronic opioid therapy in chronic non cancer pain. Journal of Pain 2009;10(2):113-30. [DOI: 10.1016/j.jpain.2008.10.009]

\section{Chou 2015}

Chou R, Turner JA, Devine EB, Hansen RN, Sullivan SD, Blazina I, et al. The effectiveness and risks of long-term opioid therapy for chronic pain: a systematic review for a National Institutes of Health Pathways to Prevention Workshop. Annals of Internal Medicine 2015;162(4):276-86.

\section{Darchuk 2010}

Darchuk KM, Townsend CO, Rome JD, Bruce BK, Hooten WM. Longitudinal treatment outcomes for geriatric patients with chronic non-cancer pain at an interdisciplinary pain rehabilitation program. Pain Medicine 2010;11(9):1352-64. [DOI: 10.1111/j.1526-4637.2010.00937.x]

\section{Deeks 2011}

Deeks JJ, Higgins JPT, Altman DG (editors). Chapter 9: Analysing data and undertaking meta-analyses. In: Higgins JPT, Green $\mathrm{S}$ (editors). Cochrane Handbook for Systematic Reviews of Interventions Version 5.1.0 (updated March 2011). The Cochrane Collaboration, 2011. Available from handbook.cochrane.org.

\section{2009}

Department of Labor \& Industries. Interim evaluation of the Washington State interagency guideline on opioid dosing for chronic non-cancer pain, 2009. www.agencymeddirectors.wa.gov/Files/AGReportFinal.pdf (accessed 24 April 2013).

\section{Dowell 2016}

Dowell D, Haegerich TM, Chou R. CDC guideline for prescribing opioids for chronic pain-United States, 2016. JAMA 2016;315(15):1624-45.

\section{Franklin 2012}

Franklin GM, Mai J, Turner J, Sullivan M, Wickizer T, FultonKehoe D. Bending the prescription opioid dosing and mortality curves: impact of the Washington State opioid dosing guideline. American Journal of Industrial Medicine 2012;55(4):325-31. [DOI: 10.1002/ajim.21998]

\section{Furlan 2006}

Furlan AD, Sandoval JA, Mailis-Gagnon A, Tunks E. Opioids for chronic non-cancer pain: a meta-analysis of effectiveness and side effects. Canadian Medical Association Journal 2006;174(11):1589-94. [DOI: 10.1503/cmaj.051528]

\section{Gallagher 2009}

Gallagher AM, Leighton-Scott J, Van Staa TP. Utilization characteristics and treatment persistence in patients prescribed low-dose buprenorphine patches in primary care in the United Kingdom: a retrospective cohort study. Clinical Therapeutics 2009;31(8):1707-15. [DOI: 10.1016/j.clinthera.2009.08.022]

\section{Gowing 2009}

Gowing L, Ali R, White JM. Opioid antagonists with minimal sedation for opioid withdrawal. Cochrane Database of Systematic Reviews 2009, Issue 4. Art. No: CD002021. [DOI: 10.1002/14651858.CD002021.pub3]

\section{Gowing 2010}

Gowing L, Ali R, White JM. Opioid antagonists under heavy sedation or anaesthesia for opioid withdrawal. Cochrane Database of Systematic Reviews 2010, Issue 1. Art. No: CD002022. [DOI: 10.1002/14651858.CD002022.pub3]

\section{Guy 2017}

Guy GP Jr, Zhang K, Bohm MK, Losby J, Lewis B, Young R, et al. Vital Signs: Changes in Opioid Prescribing in the United States, 2006-2015. Morbitity and Mortality Weekly Report, Center for Disease Control and Prevention 2017;66:697-704. [DOI: 10.15585/mmwr.mm6626a4]

\section{HB2876 2010}

State of Washington. Engrossed Substitute House Bill 2876, 2010. apps.leg.wa.gov/documents/billdocs/2009-10/Pdf/Bills/ House\%20Bills/2876-S.E.pdf (accessed 24 April 2013).

\section{Higgins 2003}

Higgins JPT, Thompson SG, Deeks JJ, Altman DG. Measuring inconsistency in meta-analyses. BMJ 2003;327:557-60.

\section{Higgins 2011}

Higgins JPT, Altman DG, Sterne JAC (editors). Chapter 8: Assessing risk of bias in included studies. In: Higgins JPT, Green $\mathrm{S}$ (editors). Cochrane Handbook for Systematic Reviews of 
Interventions Version 5.1.0 (updated March 2011). The Cochrane Collaboration, 2011. Available from handbook.cochrane.org.

\section{Hooten 2007}

Hooten WM, Townsend CO, Sletten CD, Bruce BK, Rome JD. Treatment outcomes after multidisciplinary pain rehabilitation with analgesic medication withdrawal for patients with fibromyalgia. Pain Medicine 2007;8(1):8-16. [DOI: 10.1111/ j.1526-4637.2007.00253.x]

\section{Hooten 2009}

Hooten WM, Townsend CO, Bruce BK, Warner DO. The effects of smoking status on opioid tapering among patients with chronic pain. Anesthesia and Analgesia 2009;108(1):308-15. [DOI: 10.1213/ane.0b013e31818c7b99]

\section{Kalso 2004}

Kalso E, Edwards JE, Moore RA, McQuay HJ. Opioids in chronic non-cancer pain: systematic review of efficacy and safety. Pain 2004;112(3):372-80. [DOI: 10.1016/j.pain.2004.09.019]

\section{Mayo 2017}

Anon. Pain Rehabilitation Center in Minnesota, 2017. www.mayoclinic.org/departments-centers/pain-rehabilitationcenter/overview (accessed 1st November 2017).

\section{Miller 2011}

Miller M, Stürmer T, Azrael D, Levin R, Solomon DH. Opioid analgesics and the risk of fractures in older adults with arthritis. Journal of the American Geriatrics Society 2011;59:430-8. [DOI: 10.1111/j.1532-5415.2011.03318.x]

\section{Moore 2005}

Moore RA, McQuay HJ. Prevalence of opioid adverse events in chronic non-malignant pain: systematic review of randomised trials of oral opioids. Arthritis Research and Therapy 2005;7(5):R1046-51. [DOI: 10.1186/ar1782]

\section{Moore 2008}

Moore RA, Barden J, Derry S, McQuay HJ. Managing potential publication bias. In: McQuay HJ, Kalso E, Moore RA, editors(s). Systematic Reviews in Pain Research: Methodology Refined. Seattle: IASP Press, 2008. [DOI: 978-0-931092-69-5]

\section{Moore 2012}

Moore RA, Straube S, Eccleston C, Derry S, Aldington D, Wiffen P, et al. Estimate at your peril: imputation methods for patient withdrawal can bias efficacy outcomes in chronic pain trials using responder analyses. Pain 2012;153(2):265-8. [DOI: 10.1016/j.pain.2011.10.004]

\section{Moore 2013}

Moore RA, Derry S, Taylor RS, Straube S, Phillips CJ. The costs and consequences of adequately managed chronic non-cancer pain and chronic neuropathic pain. Pain Practice 2014;14(1):79-94. [DOI: 10.1111/papr.12050]

\section{Morasco 2010}

Morasco BJ, Duckart JP, Carr TP, Deyo RA, Dobscha SK. Clinical characteristics of veterans prescribed high doses of opioid medications for chronic non-cancer pain. Pain 2010;151(3):625-32. [DOI: 10.1016/j.pain.2010.08.002]

\section{Noble 2010}

Noble M, Treadwell JR, Tregear SJ, Coates VH, Wiffen PJ, Akafomo C, et al. Long-term opioid management for chronic noncancer pain. Cochrane Database of Systematic Reviews 2010, Issue 1. Art. No: CD006605. [DOI: 10.1002/14651858.CD006605.pub2]

\section{Paulozzi 2011}

Paulozzi LJ, Jones CM, Mack KA, Rudd RA. Vital signs: overdoses of prescription opioid pain relievers, United States, 1999-2008. Morbidity and Mortality Weekly Report 2011;60(43):1487-92.

\section{RevMan 2014 [Computer program]}

Nordic Cochrane Centre, The Cochrane Collaboration Review Manager 5 (RevMan 5). Version 5.3. Copenhagen: Nordic Cochrane Centre, The Cochrane Collaboration, 2014.

\section{Schünemann 2011}

Schünemann HJ, Oxman AD, Vist GE, Higgins JPT, Deeks JJ, Glasziou P, et al. Chapter 12: Interpreting results and drawing conclusions. In: Higgins JPT, Green S (editors), Cochrane Handbook for Systematic Reviews of Interventions Version 5.1.0 (updated March 2011). The Cochrane Collaboration, 2011. Available from handbook.cochrane.org.

\section{Solomon 2010}

Solomon DH, Rassen JA, Glynn RJ, Lee J, Levin R, Schneeweiss $\mathrm{S}$. The comparative safety of analgesics in older adults with arthritis. Archives of Internal Medicine 2010;170(1):1968-76. [DOI: 10.1001/archinternmed.2010.391]

\section{Stannard 2012}

Stannard C. Opioid prescribing in the UK: can we avert a public health disaster? British Journal of Pain 2012;6(1):7-8. [DOI: $10.1177 / 2049463712439131$ ]

\section{Steiner 2011}

Steiner DJ, Sitar S, Wen W, Sawyerr G, Munera C, Ripa SR, et al. Efficacy and safety of the seven-day buprenorphine transdermal system in opioid-naïve patients with moderate to severe chronic low back pain: an enriched, randomized, double-blind, placebo-controlled study. Journal of Pain Symptom Management 2011;42(6):903-17. [DOI: 10.1016/ j.jpainsymman.2011.04.006]

\section{Sullivan 2010}

Sullivan MD, Edlund MJ, Fan M, Devries A, Brennan Braden J, Martin BC. Risks for possible and probable opioid misuse among recipients of chronic opioid therapy in commercial and Medicaid insurance plans: the TROUP study. Pain 2010;150(2):332-9. [DOI: 10.1016/j.pain.2010.05.020]

\section{Washington State Agency Medical Group 2010}

Washington State Agency Medical Director's Group. Interagency guideline on opioid dosing for chronic non-cancer pain: an educational aid to improve care and safety with opioid therapy, 2010. www.agencymeddirectors.wa.gov/ (accessed 15 April 2013). 


\section{Williams 2012}

Williams ACDC, Eccleston C, Morley S. Psychological therapies for the management of chronic pain (excluding headache) in adults. Cochrane Database of Systematic Reviews 2012, Issue 11. Art. No: CD007407. [DOI: 10.1002/14651858.CD007407.pub3]

\section{References to other published versions of this review \\ Windmill 2013}

Windmill J, Fisher E, Eccleston C, Derry S, Stannard C, Knaggs R, et al. Interventions for the reduction of prescribed opioid use in chronic non-cancer pain. Cochrane Database of Systematic Reviews 2013, Issue 9. Art. No: CD010323. [DOI: 10.1002/14651858.CD010323.pub2]

* Indicates the major publication for the study

\section{CHARACTERISTICS OF STUDIES}

Characteristics of included studies [ordered by study ID]

Garland 2014

\section{Study characteristics}

\begin{tabular}{ll}
\hline Methods & Randomised, 8-week, active-control RCT \\
& Assessments at pre-post treatment and 3-month follow-up \\
\hline Participants & Chronic pain condition: mixed (including fibromyalgia, arthritis, cervicalgia, lumbago, and other) \\
& 115 participants were randomised, MORE $(n=57)$, support group ( $n=58)$ \\
& Female 78; male 37 \\
& Mean age $=48$ years, SD $=13$ years
\end{tabular}

Interventions Mindfulness-oriented recovery enhancement (MORE): delivered to participants in 8 two-h sessions by a Master's level clinical social worker with $>10$ years of clinical experience. 15-min homework sessions were given to be practiced daily

Support group: 8 two-h sessions for participants to discuss topics pertinent to chronic pain and longterm opioid use were discussed. Topics were designed to match sessions in the MORE group. Lead by a Master's level clinical social worker

Outcomes Prescribed medication use: no measure of prescription. Measures of desire for opioids and Current Opioid Misuse Measure were included

Pain: BPI, pain severity subscale

Psychological function: CSQ; Calgary Symptoms of Stress Inventory

Physical function: BPI, pain interference subscale

Funded by National Institute on Drug Abuse and a grant from Fahs-Beck Fund for Research and Experi-
mentalation

\section{Risk of bias}

\begin{tabular}{lll}
\hline Bias & Authors' judgement & Support for judgement \\
\hline $\begin{array}{l}\text { Random sequence genera- } \\
\text { tion (selection bias) }\end{array}$ & Low risk & $\begin{array}{l}\text { "Participants were randomly allocated to MORE or to the SG. Order of ran- } \\
\text { domisation was computer generate via simple randomisation blocks of vary- } \\
\text { ing sizes (6-8) to preserve unpredictability of allocation." }\end{array}$ \\
\hline $\begin{array}{l}\text { Allocation concealment } \\
\text { (selection bias) }\end{array}$ & Low risk & $\begin{array}{l}\text { "Order of randomisation was computer generated via simple randomisation } \\
\text { blocks of varying sizes (6-8) to preserve unpredictability of allocation." }\end{array}$ \\
\hline
\end{tabular}


Garland 2014 (Continued)
Blinding of outcome as-
Low risk
"Assessments were conducted by project staff blind to each respondent's sessment (detection bias) group assignment, which was concealed throughout the study".

All outcomes

\begin{tabular}{|c|c|c|}
\hline $\begin{array}{l}\text { Incomplete outcome data } \\
\text { (attrition bias) }\end{array}$ & Unclear risk & $\begin{array}{l}\text { Attrition is described but analyses of differences between completers and non } \\
\text { completers was not conducted. }\end{array}$ \\
\hline
\end{tabular}

All outcomes completers was not conducted.

Selective reporting (re- Low risk Comprehensive reporting of outcomes
porting bias)

Size High risk 42/46 received at least 1 session

Jamison 2010

\section{Study characteristics}

\begin{tabular}{ll}
\hline Methods & Randomised trial, standard medical care control \\
& Assessments at baseline and 6 months \\
\hline Participants & $\begin{array}{l}\text { Chronic pain patients with a history or risk of opioid misuse. All participants had chronic back or neck } \\
\text { pain. }\end{array}$ \\
& 42 patients were randomised; CBT $(n=21)$, standard medical care $(n=21)$ \\
& Female $20 ;$ male 22 \\
& Mean age $=46.79$ years, $S D=7.27$ years
\end{tabular}

Interventions

CBT for prevention of opioid misuse: group and individual sessions were delivered to participants. Treatment was composed of 5 components; electronic monthly diaries, monthly urine screens, monthly completion of the Opioid Compliance Checklist, monthly group education sessions and worksheets, individual motivational compliance counselling. Groups and individual sessions included enhancing and maintaining motivation to avoid illicit substance use, coping with urges, problem solving, and lifestyle balance. Participants were provided with discussions round risk factors, motivational counselling, homework, and completed a monthly opioid compliance checklist. Treatment lasted 6 months.

Standard medical care: no description provided

Outcomes Prescribed medication use: no measure of prescription. Measures of desire for opioids and Current
Opioid Misuse Measure were included.

Pain: BPI, pain severity subscale

Psychological function: HADS

Physical function: BPI, pain interference subscale, Pain Disability Index

$\begin{array}{ll}\text { Notes } & \text { The study was supported in part by an investigator-initiated grant from End Pharmaceuticals, Chadds } \\ \text { Ford, PA and Grants R21 DA024298, Jamison PI and K23DA020682 Wasan PI from the National Insti- } \\ \text { tute on Drug Abuse of the National Institutes of Health, Bethesda, MD, and the ARthritis Foundindation } \\ \text { (Wasan) }\end{array}$

\section{Risk of bias}

Bias Authors' judgement Support for judgement


Jamison 2010 (Continued)

Random sequence genera- High risk "...assignment to treatment group based on a randomized number list created tion (selection bias) before the start of the study. Subjects were assigned to their group in the order that they entered into the study"

\begin{tabular}{|c|c|c|}
\hline $\begin{array}{l}\text { Allocation concealment } \\
\text { (selection bias) }\end{array}$ & Unclear risk & Not described \\
\hline $\begin{array}{l}\text { Blinding of outcome as- } \\
\text { sessment (detection bias) } \\
\text { All outcomes }\end{array}$ & Unclear risk & No description provided \\
\hline $\begin{array}{l}\text { Incomplete outcome data } \\
\text { (attrition bias) } \\
\text { All outcomes }\end{array}$ & Unclear risk & $\begin{array}{l}\text { Attrition is described but analyses of differences between completers and non- } \\
\text { completers was not conducted. }\end{array}$ \\
\hline $\begin{array}{l}\text { Selective reporting (re- } \\
\text { porting bias) }\end{array}$ & High risk & Post-treatment means and SDs are not provided for all measures. \\
\hline Size & High risk & 21 per group \\
\hline
\end{tabular}

Naylor 2010

\section{Study characteristics}

\begin{tabular}{|c|c|}
\hline Methods & $\begin{array}{l}11 \text { weeks plus } 120 \text { days' duration, randomised, standard care, controlled trial. Assessments at baseline, } \\
\text { post intervention, } 4 \text { months, and } 8 \text { months post intervention }\end{array}$ \\
\hline \multirow[t]{4}{*}{ Participants } & Chronic pain condition: chronic musculoskeletal pain \\
\hline & 55 participants randomised, 51 participants received allocated intervention \\
\hline & Female 44, male 7 \\
\hline & Mean age $46(S D \pm 11.5)$ years \\
\hline \multirow[t]{3}{*}{ Interventions } & All participants received 11 90-min sessions of CBT pre-randomisation \\
\hline & Therapeutic Interactive Voice Response $(n=26)$ \\
\hline & Standard care $(n=25)$ \\
\hline \multirow[t]{4}{*}{ Outcomes } & $\begin{array}{l}\text { Prescribed medication use: dose and frequency of opioid analgesics, non-steroidal anti-inflammatory } \\
\text { drugs, benzodiazepines, and antidepressants }\end{array}$ \\
\hline & Pain: Short Form MPQ, Pain Symptoms sub scale from the TOPS \\
\hline & Psychological function: BDI, SF-36 Mental Function Scale, CSQ \\
\hline & Physical function: SF-36 Physical Function Scale, TOPS Total Pain Experience Scale \\
\hline \multirow[t]{3}{*}{ Notes } & 4 participants were excluded following randomisation. \\
\hline & This research was supported by grants from the National Institute of Drug Addiction (NIDA) R21 \\
\hline & $\begin{array}{l}\text { DA016115, National Institute of Arthritis, Musculoskeletal Diseases (NIAMS) R01 AR052131, and National } \\
\text { Institute on Alcohol Abuse and Alcoholism (NIAAA) R01 AA014270. }\end{array}$ \\
\hline
\end{tabular}

\section{Risk of bias}


Naylor 2010 (Continued)

\begin{tabular}{lll} 
Bias & Authors' judgement & Support for judgement \\
\hline $\begin{array}{l}\text { Random sequence genera- } \\
\text { tion (selection bias) }\end{array}$ & Unclear risk & "Randomized using a stratified block design" \\
\hline $\begin{array}{l}\text { Allocation concealment } \\
\text { (selection bias) }\end{array}$ & Low risk & $\begin{array}{l}\text { "consecutively numbered, sealed envelopes were prepared for each gender } \\
\text { group by the statistician" }\end{array}$ \\
\hline $\begin{array}{l}\text { Blinding of outcome as- } \\
\text { sessment (detection bias) } \\
\text { All outcomes }\end{array}$ & Unclear risk & Not described \\
\hline $\begin{array}{l}\text { Incomplete outcome data } \\
\text { (attrition bias) } \\
\text { All outcomes }\end{array}$ & Low risk & No dropouts during the study \\
\hline $\begin{array}{l}\text { Selective reporting (re- } \\
\text { porting bias) }\end{array}$ & Low risk & \\
\hline $\begin{array}{l}\text { Size } \\
\text { High risk }\end{array}$ & Comprehensive reporting of outcomes \\
\hline
\end{tabular}

\section{Sullivan 2017}

\section{Study characteristics}

Methods Non-blinded RCT. 18-week intervention. Assessments at baseline, 22 weeks, and 34 weeks

\begin{tabular}{ll}
\hline Participants & Chronic pain condition: chronic non-cancer pain \\
& 35 participants randomised, 18 to taper support; 17 to usual care \\
& Female 25 , male 10 \\
& Mean age 54.4 years $(S D=10.1)$
\end{tabular}

Interventions

All participants were shown a 14-min video of patients who had successfully tapered off opioids before randomisation.

Opioid tapering group: participants underwent motivational interviewing and then 17 30-min weekly sessions with Physician Assistant delivering CBT and occasional motivational interviewing. Booster phone calls were scheduled at 24, 39, and 32 weeks. Sessions were conducted in person and over the phone. Participants received workbooks and CDs throughout treatment. Participants' opioid medication was tapered $10 \%$ for the first 3 weeks, then reassessed and reduced $10 \%$ for the following weeks. Participants could pause tapering, but were not allowed to remain in the study if they increased opioid prescription.

Usual care: participants in the control group received usual care from physicians, with no restrictions on medications during the study period.

Outcomes

Prescribed medication use: mean daily opioid dose

Pain:BPI, pain severity subscale

Psychological function: Patient Health Questionnaire-9 (depression)

Physical function: BPI, pain interference subscale 
Sullivan 2017 (Continued)

Notes

This work was supported by Grant R34DA033384 from the National Institute on Drug Abuse to Mark Sullivan.

Dr. Sullivan reports consulting with Chrono Therapeutics. Other authors report no conflicts of interest.

\section{Risk of bias}

\begin{tabular}{|c|c|c|}
\hline Bias & Authors' judgement & Support for judgement \\
\hline $\begin{array}{l}\text { Random sequence genera- } \\
\text { tion (selection bias) }\end{array}$ & Low risk & $\begin{array}{l}\text { "Study participants were randomized 1:1 to receive either the opioid taper in- } \\
\text { tervention or usual care according to a computer-generated randomisation list } \\
\text { in sealed envelopes" }\end{array}$ \\
\hline $\begin{array}{l}\text { Allocation concealment } \\
\text { (selection bias) }\end{array}$ & Low risk & $\begin{array}{l}\text { "Study participants were randomized 1:1 to receive either the opioid taper in- } \\
\text { tervention or usual care according to a computer-generated randomisation list } \\
\text { in sealed envelopes" }\end{array}$ \\
\hline $\begin{array}{l}\text { Blinding of outcome as- } \\
\text { sessment (detection bias) } \\
\text { All outcomes }\end{array}$ & Unclear risk & Not described \\
\hline $\begin{array}{l}\text { Incomplete outcome data } \\
\text { (attrition bias) } \\
\text { All outcomes }\end{array}$ & Unclear risk & $\begin{array}{l}\text { Attrition is described but analyses of differences between completers and non- } \\
\text { completers was not conducted. }\end{array}$ \\
\hline $\begin{array}{l}\text { Selective reporting (re- } \\
\text { porting bias) }\end{array}$ & Low risk & All outcomes reported \\
\hline Size & High risk & $17 / 18$ per treatment arm \\
\hline
\end{tabular}

\section{Zheng 2008}

\section{Study characteristics}

\begin{tabular}{|c|c|}
\hline Methods & $\begin{array}{l}20 \text { weeks, randomised, single-blind, sham-controlled trial } \\
\text { Assessments at baseline and at weeks 5, 8, 12, 16, and } 20\end{array}$ \\
\hline Participants & $\begin{array}{l}35 \text { participants with non-malignant pain for }>3 \text { months, using opioid medication } \\
\text { Female } 17 \text {, male } 18 \\
\text { Mean age } 50 \text { years (SD }=11 \text { years) }\end{array}$ \\
\hline Interventions & $\begin{array}{l}\text { Electroacupuncture }(n=17) \text { for } 20 \text { min twice/week for } 6 \text { weeks } \\
\text { Sham electroacupuncture }(n=18) \text { for } 20 \text { min twice/week for } 6 \text { weeks }\end{array}$ \\
\hline Outcomes & $\begin{array}{l}\text { Prescribed opioid use: dosage of opioid-like medications and adverse events (type and frequency) } \\
\text { Pain: pain intensity-visual analogue scale; MPQ } \\
\text { Psychological function: BDI } \\
\text { Physical function: none } \\
\text { SF-36 v2 Health Survey }\end{array}$ \\
\hline
\end{tabular}


Zheng 2008 (Continued)

Notes
The study was supported by a research grant provided by the then Faculty of Life Sciences, RMIT University. Ms. Jessica Guo, a research candidate, was supported by an Australian Postgraduate Award (APA) and an Australian Acupuncture and Chinese Medicine Association (AACMA) Research Grant 2005

\section{Risk of bias}

\begin{tabular}{lll}
\hline Bias & Authors' judgement & Support for judgement \\
\hline $\begin{array}{l}\text { Random sequence genera- } \\
\text { tion (selection bias) }\end{array}$ & Low risk & $\begin{array}{l}\text { "Block randomisation code was computer generated and stored in a password } \\
\text { protected computer" }\end{array}$ \\
\hline $\begin{array}{l}\text { Allocation concealment } \\
\text { (selection bias) }\end{array}$ & Unclear risk & Not described \\
\hline $\begin{array}{l}\text { Blinding of outcome as- } \\
\text { sessment (detection bias) } \\
\text { All outcomes }\end{array}$ & Unclear risk & Single blind \\
\hline $\begin{array}{l}\text { Incomplete outcome data } \\
\text { (attrition bias) } \\
\text { All outcomes }\end{array}$ & Unclear risk & $\begin{array}{l}\text { Attrition is described but analyses of differences between completers and non- } \\
\text { completers was not conducted. }\end{array}$ \\
\hline $\begin{array}{l}\text { Selective reporting (re- } \\
\text { porting bias) }\end{array}$ & Low risk & All data reported. Last observation carried forward used for 9/35. \\
\hline \begin{tabular}{l} 
Size \\
\hline
\end{tabular} & High risk & $17 / 18$ per treatment arm \\
\hline
\end{tabular}

BDI: Beck Depression Inventory

BPI: Brief Pain Inventory

CBT: cognitive behavioural therapy

CSQ: Coping Strategies Questionnaire

HADS: Hospital Anxiety and Depression Scale

MPQ: McGIll Pain Questionnaire

$\mathrm{RCT}$ : randomised controlled trial

TOPS: Treatment Outcomes in Pain Survey

Characteristics of excluded studies [ordered by study ID]

\begin{tabular}{ll}
\hline Study & Reason for exclusion \\
\hline Crisostomo 2008 & Not randomised \\
\hline Hale 2007 & Primary aim of study was not opioid reduction \\
\hline Krymchantowski 2003 & $<10$ participants in each arm at post-treatment \\
\hline Potter 2010 & Primary aim of study was not opioid reduction \\
\hline Roland 2011 & Primary aim of study was not opioid reduction \\
\hline Townsend 2008 & Not randomised \\
\hline Weinstein 2006 & Primary aim of study was not opioid reduction \\
\hline
\end{tabular}


Characteristics of ongoing studies [ordered by study ID]

NCT02602535

\begin{tabular}{|c|c|}
\hline Study name & $\begin{array}{l}\text { Mindfulness-oriented recovery enhancement for chronic pain and prescription opioid misuse in } \\
\text { primary care }\end{array}$ \\
\hline Methods & $\mathrm{RCT}$, single-blind \\
\hline Participants & People with chronic pain \\
\hline Interventions & Mindfulness-oriented recovery enhancement vs support group \\
\hline \multirow[t]{12}{*}{ Outcomes } & Primary outcomes (baseline to 6 months) \\
\hline & $\begin{array}{l}\text { Current Opioid Misuse and/or Addiction Behaviors Checklist and/or urine screen (triangulation ag- } \\
\text { gregate) - change in opioid misuse }\end{array}$ \\
\hline & $\mathrm{BPI}$ - pain severity and interference \\
\hline & Secondary outcomes \\
\hline & Change in opioid craving \\
\hline & Depression Anxiety Stress Scale \\
\hline & Opioid doses converted into morphine equivalents \\
\hline & Other outcomes \\
\hline & Change in nonreactivity \\
\hline & CSQ \\
\hline & Cognition Emotion Regulation Questionnaire \\
\hline & Ways of Savoring Checklist \\
\hline Starting date & 2016 \\
\hline Contact information & Dr Eric Garland, University of Utah \\
\hline Notes & $\begin{array}{l}\text { clinicaltrials.gov/ct2/show/NCT02602535?term=Mindfulness-Oriented+Recovery+Enhancemen- } \\
\text { t\&rank=1 }\end{array}$ \\
\hline
\end{tabular}

NCT02935621

\begin{tabular}{ll}
\hline Study name & Behavioral interventions for active duty service members and veterans with chronic pain \\
\hline Methods & RCT, single-blind \\
\hline Participants & Active duty service members and veterans with chronic pain conditions \\
\hline Interventions & Mindfulness-oriented recovery enhancement vs support group \\
\hline
\end{tabular}

Outcomes

Primary outcomes (baseline to 6 months)

Current Opioid Misuse and/or Addiction Behaviors Checklist and/or urine screen (triangulation aggregate) - change in opioid misuse 
NCT02935621 (Continued)

BPI - pain severity and interference

\section{Secondary outcomes}

Change in opioid craving

Depression Anxiety Stress Scal

Opioid doses converted into morphine equivalents

Post-traumatic checklist - military version

Response to Stressful Events Scale

\section{Other outcomes}

Change in nonreactivity

CSQ

Cognition Emotion Regulation Questionnaire

Ways of Savoring Checklist

\begin{tabular}{ll}
\hline Starting date & 2016 \\
\hline Contact information & Dr Eric Garland, University of Utah \\
\hline Notes & $\begin{array}{l}\text { clinicaltrials.gov/ct2/show/NCT02935621?term=Mindfulness-Oriented+Recovery+Enhancemen- } \\
\text { t\&rank=4 }\end{array}$ \\
\hline
\end{tabular}

BPI: Brief Pain Inventory

CSQ: Coping Strategies Questionnaire

$\mathrm{RCT}$ : randomised controlled trial

\section{APPENDICES}

\section{Appendix 1. Search strategies}

\section{CENTRAL search strategy}

1. MESH DESCRIPTOR Pain EXPLODE ALL TREES

2. MESH DESCRIPTOR Fibromyalgia EXPLODE ALL TREES

3. MESH DESCRIPTOR Headache Disorders EXPLODE ALL TREES

4. MESH DESCRIPTOR Arthritis EXPLODE ALL TREES

5. ((( pain $^{\star}$ or headache* or migraine ${ }^{\star}$ or neuralgia* or neuropath* or arthriti* or osteoarthriti $\left.{ }^{\star}\right)$ not cancer $\left.\left.{ }^{\star}\right)\right): T I, A B, K Y$

6. \#1 OR \#2 OR \#3 OR \#4 OR \#5

7. MESH DESCRIPTOR Analgesics, Opioid EXPLODE ALL TREES

8. ((morphine or meperidine or methadone or buprenorphine or fentanyl or hydrocodone or oxycodone or codeine)): $T \mathrm{I}, \mathrm{AB}, \mathrm{KY}$

9. ((opioid* or opiate* or papaver)):TI,AB,KY

10.MESH DESCRIPTOR Narcotics EXPLODE ALL TREES

11.\#7 OR \#8 OR \#9 OR \#10

12.MESH DESCRIPTOR Rehabilitation EXPLODE ALL TREES

13.rehabilitation:TI,AB,KY

14.MESH DESCRIPTOR Opiate Substitution Treatment EXPLODE ALL TREES

15.MESH DESCRIPTOR Narcotic Antagonists EXPLODE ALL TREES

16.((diprenophine or nalmefene or nalorphine or naloxone or naltrexone or methadone or buprenorphine or clonidine or lofexidine or guanfacine)):TI,AB,KY 
17.MESH DESCRIPTOR Psychotherapy EXPLODE ALL TREES

18.psychotherap*:TI,AB,KY

19. (((cogniti* or behaviour $^{\star}$ or behavior ${ }^{\star}$ or family or psychosocial $\left.{ }^{\star}\right)$ near5 (therap ${ }^{\star}$ or intervention $\left.\left.\left.{ }^{\star}\right)\right)\right): \mathrm{TI}, \mathrm{AB}, \mathrm{KY}$

20. ((counsel ${ }^{*}$ or cope or coping)):TI,AB,KY

21.MESH DESCRIPTOR Physical Therapy Modalities EXPLODE ALL TREES

22.MESH DESCRIPTOR Mind-Body Therapies EXPLODE ALL TREES

23. ((physical ${ }^{\star}$ near5 therap $\left.\left.{ }^{\star}\right)\right): \mathrm{TI}, \mathrm{AB}, \mathrm{KY}$

24. physiotherap*:TI,AB,KY

25.((biofeedback ${ }^{\star}$ or massage* or acupuncture)):TI,AB,KY

26.MESH DESCRIPTOR pastoral care

27.MESH DESCRIPTOR spirituality

28.MESH DESCRIPTOR Adaptation, Psychological

29. ((well being or well-being or relax ${ }^{\star}$ or accept $^{\star}$ or meditat ${ }^{\star}$ or spiritual $\left.\left.{ }^{\star}\right)\right): \mathrm{TI}, \mathrm{AB}, \mathrm{KY}$

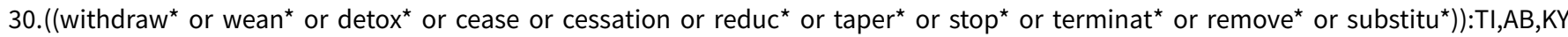
withdraw ${ }^{\star}$ or wean ${ }^{\star}$ or detox ${ }^{\star}$ or cease or cessation or reduc ${ }^{\star}$ or taper $^{\star}$ or stop* or terminat $^{\star}$ or remove* or substitu* $^{\star}$

31.\#12 OR \#13 OR \#14 OR \#15 OR \#16 OR \#17 OR \#18 OR \#19 OR \#20 OR \#21 OR \#22 OR \#23 OR \#24

32.\#6 AND \#11 AND \#31

33.MESH DESCRIPTOR Pain, Postoperative EXPLODE ALL TREES

34.\#32 NOT \#33

\section{MEDLINE search strategy (via Ovid)}

1. exp Pain, Intractable/ or exp Chronic Pain/

2. Fibromyalgia/

3. exp Headache Disorders/

4. exp Arthritis/

5. (pain ${ }^{\star}$ or headache ${ }^{\star}$ or migraine ${ }^{\star}$ or neuralgia* or neuropath $^{\star}$ or arthriti ${ }^{\star}$ or osteoarthriti $\left.{ }^{\star}\right) . \mathrm{mp}$.

6. 1 or 2 or 3 or 4 or 5

7. exp Analgesics, Opioid/

8. (morphine or meperidine or methadone or buprenorphine or fentanyl or hydrocodone or oxycodone or codeine).mp.

9. (opioid* or opiate* or papaver).mp.

10.exp Narcotics/

11.7 or 8 or 9 or 10

12.exp Rehabilitation/

13. rehabilitation.fs.

14.Opiate Substitution Treatment/

15.exp Narcotic Antagonists/

16. (diprenophine or nalmefene or nalorphine or naloxone or naltrexone or methadone or buprenorphine or clonidine or lofexidine or guanfacine).mp.

17.exp Psychotherapy/

18. psychotherap*.mp.

19. ((cogniti* or behaviour ${ }^{\star}$ or behavior ${ }^{\star}$ or family or psychosocial $\left.{ }^{\star}\right)$ adj5 (therap ${ }^{\star}$ or intervention $\left.\left.{ }^{\star}\right)\right) . m p$.

20. (counsel ${ }^{\star}$ or cope or coping).mp.

21.exp Physical Therapy Modalities/

22.exp Mind-Body Therapies/

23. (physical* ${ }^{\star}$ adj5 therap $\left.{ }^{\star}\right)$.mp.

24. physiotherap $\left.{ }^{\star}\right) \cdot m p$.

25. (biofeedback ${ }^{\star}$ or massage ${ }^{\star}$ or acupuncture).mp.

26. pastoral care/ or spirituality/

27.Adaptation, Psychological/

28. (well being or well-being or relax* or accept $^{\star}$ or meditat $^{\star}$ or spiritual ${ }^{\star}$ ).mp.

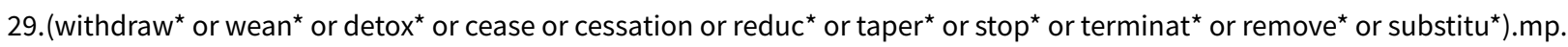

30.or/12-29 
31.6 and 11 and 30

32.randomized controlled trial.pt.

33. controlled clinical trial.pt.

34.randomized.ab.

35. placebo.ab.

36.drug therapy.fs.

37.randomly.ab.

38.trial.ab.

39. groups.ab.

40.32 or 33 or 34 or 35 or 36 or 37 or 38 or 39

41.exp animals/ not humans.sh.

42.40 not 41

43.31 and 42

44. (post-operative or postoperative).mp.

45.43 not 44

46.limit 45 to ("young adult (19 to 24 years)" or "adult (19 to 44 years)" or "young adult and adult (19-24 and 19-44)" or "middle age (45 to 64 years)" or "middle aged (45 plus years)" or "all aged (65 and over)" or "aged (80 and over)")s)" or "all aged (65 and over)" or "aged (80 and over)")

\section{Embase search strategy (via Ovid)}

1. exp chronic pain/ or exp intractable pain/

2. Fibromyalgia/

3. exp Headache Disorders/

4. exp Arthritis/

5. ((pain ${ }^{\star}$ or headache* or migraine ${ }^{\star}$ or neuralgia* or neuropath* or arthriti ${ }^{\star}$ or osteoarthriti $\left.{ }^{\star}\right)$ not cancer $\left.{ }^{\star}\right) \cdot \mathrm{mp}$. [mp=title, abstract, original title, name of substance word, subject heading word, keyword heading word, protocol supplementary concept word, rare disease supplementary concept word, unique identifier]

6. or/1-5

7. exp Analgesics, Opioid/

8. (morphine or meperidine or methadone or buprenorphine or fentanyl or hydrocodone or oxycodone or codeine).mp. [mp=title, abstract, original title, name of substance word, subject heading word, keyword heading word, protocol supplementary concept word, rare disease supplementary concept word, unique identifier]

9. (opioid* or opiate* or papaver).mp. [mp=title, abstract, original title, name of substance word, subject heading word, keyword heading word, protocol supplementary concept word, rare disease supplementary concept word, unique identifier]

10.exp Narcotics/

11.or/7-10

12.exp Rehabilitation/

13.rehabilitation.fs.

14.Opiate Substitution Treatment/

15.exp Narcotic Antagonists/

16. (diprenorphine or nalmefene or nalorphine or naloxone or naltrexone or methadone or buprenorphine or clonidine or lofexidine or guanfacine).mp. [mp=title, abstract, original title, name of substance word, subject heading word, keyword heading word, protocol supplementary concept word, rare disease supplementary concept word, unique identifier]

17.exp Psychotherapy/

18.psychotherap ${ }^{\star} \cdot \mathrm{mp}$.

19. ((cogniti* or behaviour ${ }^{\star}$ or behavior ${ }^{\star}$ or family or psychosocial $\left.{ }^{\star}\right)$ adj5 (therap ${ }^{\star}$ or intervention $\left.\left.{ }^{\star}\right)\right) . m p$.

20. (counsel* or cope or coping).mp.

21.exp Physical Therapy Modalities/

22.exp Mind-Body Therapies/

23. physical $^{\star}$ adj5 therap*).mp.

24. physiotherap*.mp.

25. (biofeedback* or massage* or acupuncture).mp.

26. pastoral care/ or spirituality/

27.Adaptation, Psychological/

Interventions for the reduction of prescribed opioid use in chronic non-cancer pain (Review)

Copyright @ 2017 The Cochrane Collaboration. Published by John Wiley \& Sons, Ltd. 
28. (well being or well-being or relax ${ }^{\star}$ or accept ${ }^{\star}$ or meditat ${ }^{\star}$ or spiritual $\left.{ }^{\star}\right) . \mathrm{mp}$.

29. (withdraw* ${ }^{\star}$ or wean ${ }^{\star}$ or detox ${ }^{\star}$ or cease or cessation or reduc ${ }^{\star}$ or taper or stop $^{\star}$ or terminat ${ }^{\star}$ or remove* or substitu*).mp. 30.or/12-29

31.6 and 11 and 30

32.random\$.tw.

33.factorial\$.tw.

34.crossover\$.tw.

35.cross over\$.tw.

36.cross-over\$.tw.

37. placebo\$.tw.

38. (doubl\$ adj blind\$).tw.

39. (singl\$ adj blind\$).tw.

40.assign\$.tw.

41.allocat\$.tw.

42.volunteer\$.tw.

43. Crossover Procedure/

44.double-blind procedure.tw.

45. Randomized Controlled Trial/

46.Single Blind Procedure/

47.or/32-46

48. (animal/ or nonhuman/) not human/

49.47 not 48

50.31 and 49

Appendix 2. Additional data supplied by study authors

\begin{tabular}{|c|c|c|c|c|}
\hline Naylor 2010 & Baseline & Post treatment & 4 months & 8 months \\
\hline \multicolumn{5}{|c|}{ McGill Typical Pain } \\
\hline TIVR & $5.7 \pm 1.9$ & $5.5 \pm 1.7$ & $4.1 \pm 2.2$ & $3.4 \pm 2.4$ \\
\hline Control & $6.8 \pm 1.5$ & $5.6 \pm 1.6$ & $5.7 \pm 1.4$ & $5.7 \pm 1.7$ \\
\hline \multicolumn{5}{|l|}{ BDI } \\
\hline TIVR & $16.7 \pm 6.5$ & $10.4 \pm 6.4$ & $8.1 \pm 5.7$ & $8.1 \pm 4.8$ \\
\hline Control & $18.6 \pm 11.2$ & $16.7 \pm 11.2$ & $16.3 \pm 8.3$ & $14.9 \pm 8.7$ \\
\hline
\end{tabular}




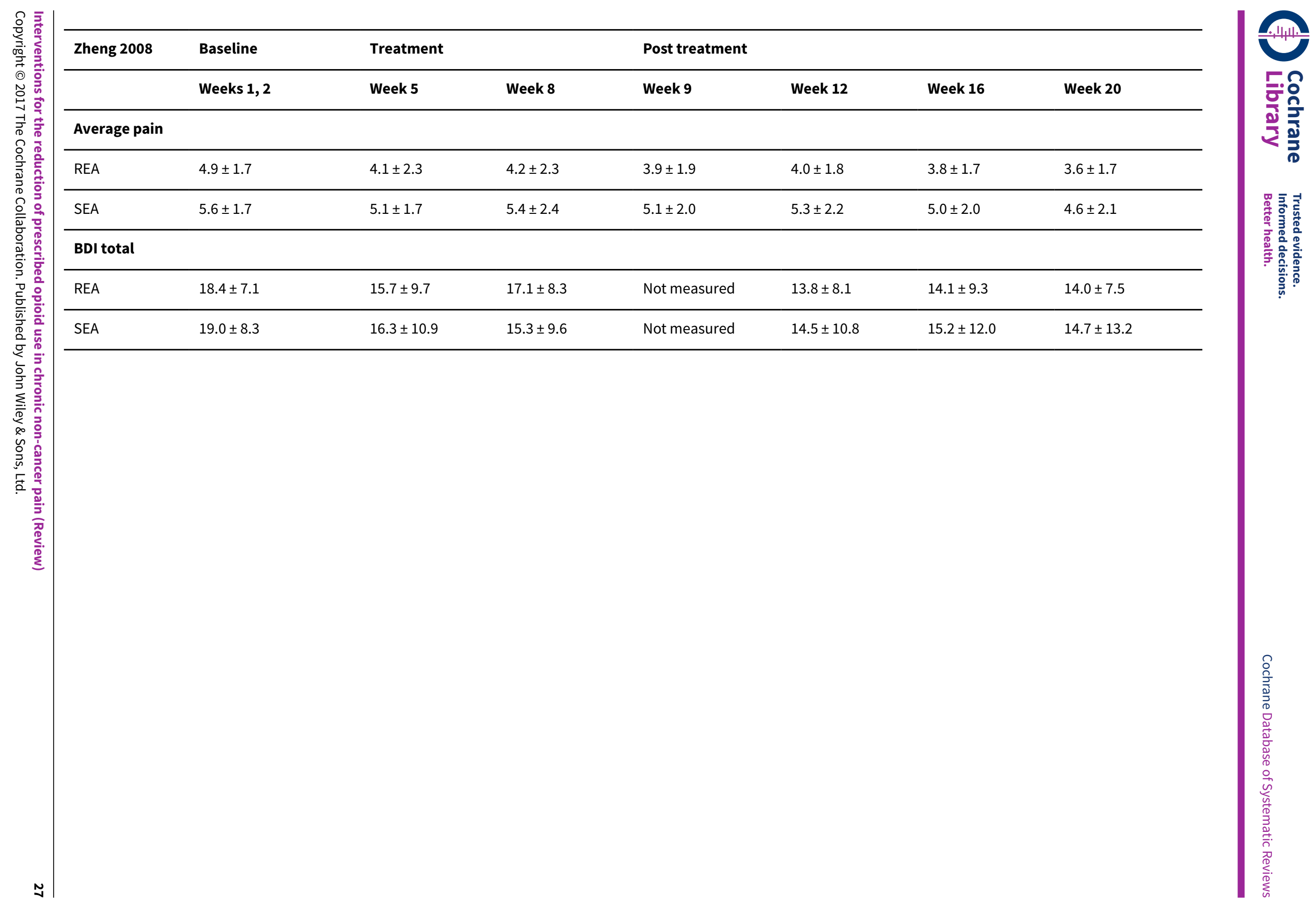


WHAT'S NEW

\begin{tabular}{lll}
\hline Date & Event & Description \\
\hline 6 May 2021 & Review declared as stable & See Published notes. \\
\hline
\end{tabular}

\section{H I S T O R Y}

Protocol first published: Issue 1, 2013

Review first published: Issue 9, 2013

\begin{tabular}{lll}
\hline Date & Event & Description \\
\hline 30 September 2019 & Amended & Clarification added to Declarations of interest. \\
\hline 19 September 2019 & Review declared as stable & See Published notes. \\
\hline 17 February 2017 & $\begin{array}{l}\text { New citation required but conclusions } \\
\text { have not changed }\end{array}$ & $\begin{array}{l}\text { We included three new studies including 192 participants in this } \\
\text { update. Conclusions have not changed. }\end{array}$ \\
\hline 17 February 2017 & New search has been performed & $\begin{array}{l}\text { This review has been updated to include the results of a new } \\
\text { search in January 2017. Three new studies were identified. }\end{array}$ \\
\hline 30 March 2016 & Amended & Contact details amended. \\
\hline
\end{tabular}

\section{CONTRIBUTIONS OF AUTHORS}

\begin{tabular}{ll}
\hline Draft the protocol & EF/CE \\
\hline Develop a search strategy & CE \\
\hline Search for studies (usually 2 authors) & EF/LH \\
\hline Obtain copies of studies & EF/LH \\
\hline Select which studies to include (2+1 arbiter) & EF/LH/CE \\
\hline Extract data from studies (2 authors) & EF/LH \\
\hline Enter data into RevMan & EF \\
\hline Carry out the analysis & $\mathrm{N} / \mathrm{A}$ \\
\hline Interpret the analysis & All authors \\
\hline Draft the final write-up of the review & EF/CE \\
\hline Update the review & CE \\
\hline Methodologist name & CE \\
\hline
\end{tabular}




\section{DECLARATIONS OF INTEREST}

CE: none known. Since CE is an author as well as the PaPaS Co-ordinating Editor at the time of writing, we acknowledge the input of Neil O'Connell who acted as Sign Off Editor for this review. CE had no input into the editorial decisions or processes for this review.

EF: none known.

KHT: none known. KHT is a public health specialist in training who is involved in the planning of health services for patients with chronic pain.

LH: none known.

SD: none known

CS: none known. CS is a consultant anaesthetist working in pain management who manages chronic pain patients who are attempting to reduce prescribed opioids.

RK has attended advisory board meetings, received honoraria or held research grants for Grunenthal (2012 to 2015), Mundipharma Research (2016 to 2019) and Actavis (2017), who market opioid analgesics.

RAM has received grant support from Grünenthal relating to individual patient-level analyses of trial data regarding tapentadol in osteoarthritis and back pain (2015). He has received honoraria for attending boards with Menarini concerning methods of analgesic trial design (2014), with Novartis (2014) about the design of network meta-analyses, and RB on understanding pharmacokinetics of drug uptake (2015). He has received honoraria from Omega Pharma (2016) and Futura Pharma (2016) for providing advice on trial and data analysis methods.

\section{SOURCES OF SUPPORT}

\section{Internal sources}

- Oxford Pain Relief Trust, UK

Institutional support

\section{External sources}

- No sources of support provided

\section{DIFFERENCES BETWEEN PROTOCOLANDREVIEW}

We did not search PsycLIT in either the first version of this protocol (Windmill 2013) or in this 2017 update, as stated in our protocol, due to the low yield and duplication between that database and the other databases searched. We contacted the authors of studies identified for inclusion to obtain additional data relevant to this review not included in the published articles. The original search for studies was intended to be completed without a time limit, but we limited inclusion to studies published in 2000 and later to reflect major changes since 2000 in prescribing of opioids to large numbers of people with chronic non-cancer pain; in this way, we worked to ensure that the review would have contemporary relevance. Although not explicitly stated in our protocol, we excluded studies of fewer than 10 participants in each treatment arm at post-treatment.

For the 2017 update, it was not possible to undertake planned data synthesis, sub-group analyses, or sensitivity analyses. We added GRADE assessment methods as is mandatory with Cochrane Reviews, however, it was not possible to conduct these assessments due to the heterogeneity of the studies. We have also removed 'blinding of personnel and participants' from the 'Risk of bias' assessment, as it is not possible to blind participants or personnel to psychological treatments. We searched trials registries for further trials not captured by our search method. We amended the first secondary outcome of 'pain intensity' to 'pain intensity/severity' for clarity.

\section{NOTES}

\section{Assessed for updating in 2019}

A restricted search in September 2019 did not identify any potentially relevant studies likely to change the conclusions. Therefore, this review has now been stabilised following discussion with the authors and editors. We are aware of several new studies which are due to be published within 2 years, and so we will reassess the review for updating in 18 months. If appropriate, we will update the review before this date if new evidence likely to change the conclusions is published, or if standards change substantially which necessitate major revisions. 


\section{Assessed for updating in 2021}

At May 2021 we are aware of two potentially relevant new studies (see below), and some ongoing studies. This review has been stabilised again following discussion with the authors and editors, and will be reassessed within two years, or when the ongoing studies are published if sooner.

\section{References}

Am Psychol. 2020 Sep;75(6):840-852. doi: 10.1037/amp0000638

Neurosurgery. 2020 Dec 15;88(1):193-201. doi: 10.1093/neuros/nyaa353

\section{IN DEX TERMS}

\section{Medical Subject Headings (MeSH)}

Analgesics, Opioid [*administration \& dosage]; Chronic Pain [drug therapy] [etiology] [*therapy]; Cognitive Behavioral Therapy $\left[{ }^{\star}\right.$ methods]; Drug Tolerance; Electroacupuncture [ ${ }^{*}$ methods]; Mindfulness; Observational Studies as Topic; Randomized Controlled Trials as Topic; Therapy, Computer-Assisted [methods]

\section{MeSH check words}

Female; Humans; Male; Middle Aged 